\title{
Test Set Embedding for Deterministic BIST Using a Reconfigurable Interconnection Network
}

\author{
Lei Li and Krishnendu Chakrabarty, Senior Member, IEEE
}

\begin{abstract}
We present a new approach for deterministic built-in self-test (BIST) in which a reconfigurable interconnection network (RIN) is placed between the outputs of a pseudorandom pattern generator and the scan inputs of the circuit under test (CUT). The RIN, which consists only of multiplexer switches, replaces the phase shifter that is typically used in pseudorandom BIST to reduce correlation between the test data bits that are fed into the scan chains. The connections between the linear-feedback shift-register (LFSR) and the scan chains can be dynamically changed (reconfigured) during a test session. In this way, the RIN is used to match the LFSR outputs to the test cubes in a deterministic test set. The control data bits used for reconfiguration ensure that all the deterministic test cubes are embedded in the test patterns applied to the CUT. The proposed approach requires very little hardware overhead, only a modest amount of CPU time, and fewer control bits compared to the storage required for reseeding techniques or for hybrid BIST. Moreover, as a nonintrusive BIST solution, it does not require any circuit redesign and has minimal impact on circuit performance.
\end{abstract}

Index Terms-Embedded core testing, system-on-a-chip (SoC) testing, test application time, test-data volume.

\section{INTRODUCTION}

$\mathbf{H}$ IGHER circuit densities and ever-increasing design complexity are placing a severe burden on the automatic test equipment (ATE) used to test today's integrated circuits (ICs). The integration of complex embedded cores in system-on-a-chip (SOC) designs is leading to a sharp increase in test-data volume, which requires significant investment in additional memory depth per ATE channel. ATE channel bandwidth is another limitation encountered in the testing of SOCs with high clock frequencies, enormous test-data volume, and a large number of I/O pins. In order to mitigate these problems, a number of techniques based on test-data compression, built-in self-test (BIST), and a combination of the two have been proposed in the literature.

In the test-data compression approach, a deterministic test set is compressed and stored in ATE memory. The compressed test set is transferred through ATE channels to the IC, where it is decompressed and applied to the circuit under test (CUT) by decoding hardware. Techniques based on statistical coding [13],

Manuscript received June 20, 2003; revised December 3, 2003. This research was supported in part by the National Science Foundation under Grants CCR-9875324 and CCR-0204077, and in part by a graduate fellowship from the Design Automation Conference. A preliminary version of this paper appeared in Proceedings of the International Test Conference, pp. 460-469, Charlotte, NC, Sept./Oct. 2003. This paper was recommended by Associate Editor S. Hellebrand.

The authors are with the Department of Electrical and Computer Engineering, Duke University, Durham, NC 27708 USA (e-mail: 11@ee.duke.edu; krish@ee.duke.edu).

Digital Object Identifier 10.1109/TCAD.2004.831593
[15], run-length coding [14], Golomb coding [6], frequency-directed run-length (FDR) coding [5], and variable-input Huffman coding (VIHC) coding [9], have been proposed to reduce testdata volume. Test-data volume-reduction techniques based on on-chip pattern decompression are also presented in [4], [8], [21], [27]-[29], and [32].

The resurgence of interest in test-data compression has also led to new commercial tools that can provide substantial compression for large industrial designs. For example, the OPMISR [3] and SmartBIST [17] tools from IBM and the TestKompress tool from Mentor Graphics [26] reduce test-data volume and testing time through the use of test-data compression and on-chip decompression.

In BIST solutions, test patterns are generated by an on-chip pseudorandom pattern generator, which is usually a linear feedback shift register (LFSR). BIST alleviates a number of problems related to test interfacing, e.g., limited-signal bandwidth and high pin count. A typical logic BIST architecture is shown in Fig. 1. In order to detect the random-pattern resistant faults and achieve complete coverage of single stuck-at faults, techniques based on test point insertion [7], [30], reseeding [2], [11], [22], [24], bit-flipping [34], bit-fixing [20], [31], [35], and weighted random pattern testing [33] have been proposed. Testpoint insertion techniques require design changes to improve random pattern testability, such that $100 \%$ fault coverage can be achieved using a reasonable number of pseudorandom test patterns. The other BIST techniques are nonintrusive in that they typically apply a limited number of random patterns; for the remaining hard-to-test faults, deterministic test patterns are obtained by either controlling the state of the pattern generator [11], [18], [22], [24] or by altering the output of the pattern generator [31], [33]-[35]. A number of studies have also been reported recently on the use of logic BIST for large industrial circuits [12], [23].

Techniques based on the combination of data compression and BIST have also been developed recently [16], [19]. The hybrid BIST scheme presented in [16] applies weighted pseudorandom patterns to the circuit to achieve $100 \%$ fault coverage. The compressed weight set is stored on ATE and decompression is carried out using an on-chip look-up table. In [19], the seeds for the LFSR are compressed using statistical coding.

In this paper, we present a new deterministic BIST approach in which a reconfigurable interconnection network (RIN) is placed between the outputs of the LFSR and the inputs of the scan chains in the CUT. The RIN, which consists only of multiplexer switches, replaces the phase shifter that is typically 
used in pseudorandom BIST to reduce correlation between the test-data bits that are fed into the scan chains. The connections between the LFSR and the scan chains can be dynamically changed (reconfigured) during a test session. In this way, the RIN is used to match the LFSR outputs to the test cubes in a deterministic test set. The control data bits used for reconfiguration ensure that all the deterministic test cubes are embedded in the test patterns applied to the CUT. The proposed approach requires very little hardware overhead, only a modest amount of CPU time, and fewer control bits compared to the storage required for reseeding techniques or for hybrid BIST. Moreover, as a nonintrusive BIST solution, it does not require any circuit redesign and has minimal impact on circuit performance.

The rest of the paper is organized as follows. Section II presents an overview of related prior work. In Section III, we present the architecture of the proposed BIST scheme and describe the procedure for the synthesis of the RIN and the determination of the control bits. In Section IV, we present a probabilistic analysis of the test set embedding technique. In Section V, we describe a strategy for declustering the care bits in the test cubes to improve the efficiency of the proposed method. Experimental results and a comparison with related recent work are presented in Section VI. Finally, Section VII concludes the paper.

\section{RELATED PRIOR WORK}

Most BIST techniques rely on the use of a limited number of pseudorandom patterns to detect the random-pattern-testable faults, which is subsequently followed by the application of a limited number of deterministic patterns to detect the randompattern-resistant faults. Based on the mechanisms that are used to generate the deterministic patterns, logic BIST techniques can be classified into two categories: methods that generate deterministic patterns by controlling the states of the LFSR [11], [18], [22], [24], and techniques that modify the patterns generated by the LFSR [31], [33], [34].

LFSR reseeding is an example of a BIST technique that is based on controlling the LFSR state. LFSR reseeding can be static, i.e., the LFSR stops generating patterns while loading seeds, or dynamic, i.e., test generation and seed loading can proceed simultaneously. The length of the seeds can be either equal to the size of the LFSR (full reseeding) or less than the size of the LFSR (partial reseeding). In [18], a dynamic reseeding technique that allows partial reseeding is proposed to encode test vectors. An LFSR of length $r \geq s_{\max }+20$, where $s_{\max }$ is the maximum number of specified bits in any deterministic test cube, is used to generate the test patterns. While the length of the first seed is $r$, the lengths of the subsequent seeds are significantly smaller than $r$. A set of linear equations is solved to obtain the seeds, and the test vectors are reordered to facilitate the solution of this set of linear equations.

A BIST pattern generator based on a folding counter is proposed in [11]. The properties of the folding counter are exploited to find the seeds needed to cover the given set of deterministic patterns. Width compression is combined with reseeding

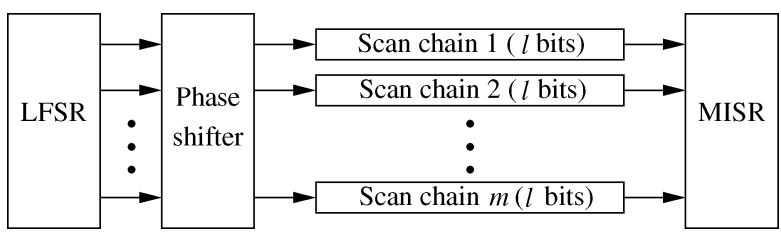

Fig. 1. Generic logic BIST architecture based on an LFSR, MISR, and phase shifter.

to reduce the hardware overhead. In [22], a two-dimensional test-data compression technique that combines an LFSR and a folding counter is proposed for scan-based BIST. LFSR reseeding is used to reduce the number of bits to be stored for each pattern (horizontal compression) and folding counter reseeding is used to reduce the number of patterns (vertical compression).

Bit-flipping, bit-fixing and weighted random BIST are examples of techniques that rely on altering the patterns generated by the LFSR to embed deterministic test cubes. In [16], a hybrid BIST method based on weighted pseudorandom testing is presented. A weight of 0,1 or u (unbiased) is assigned to each scan chain in CUT. The weight sets are compressed and stored on the tester. During test application, an on-chip look-up table is used to decompress the data from the tester and generate the weight sets. A 3-weight weighted random scan-BIST scheme is discussed in [33]. The weights in this approach are $0,0.5$, and 1. In order to reduce the hardware overhead, scan cells are carefully reordered and a special ATPG approach is used to generate suitable test cubes.

\section{PROPOSED APPROACH}

In a generic LFSR-based BIST approach shown in Fig. 1, the output of the LFSR is fed to a phase shifter to reduce the linear dependency between the data shifted into different scan chains. The phase shifter is usually a linear network composed of exclusive-or gates. In the proposed approach, illustrated in Fig. 2(a), the phase shifter is replaced by an RIN that connects the LFSR outputs to the scan chains. The RIN consists of multiplexer switches and it can be reconfigured by applying appropriate control bits to it through the inputs $D_{0}, D_{1}, \ldots, D_{g-1}$. The parameter $g$ refers to the number of configurations used during a BIST session and it is determined using a simulation procedure. The control inputs $D_{0}, D_{1}, \ldots, D_{g-1}$ are provided by a $d$-to- $g$ decoder, where $d=\left\lceil\log _{2} g\right\rceil$. A $d$-bit configuration counter is used to cycle through all possible $2^{d}$ input combinations for the decoder. The configuration counter is triggered by the BIST pattern counter, which is preset for each configuration by the binary value corresponding to the number of test patterns for the corresponding configuration. Although the elimination of the phase shifter may reduce the randomness of the pseudorandom patterns, complete fault coverage is guaranteed by the RIN synthesis procedure described later.

As shown in Fig. 2(b), the multiplexers in the RIN are implemented using tristate buffers with fully decoded control inputs. While the multiplexers can also be implemented in other ways, we use tristate buffers here because of their ease of implementation in CMOS. The outputs of the tristate buffers are connected 


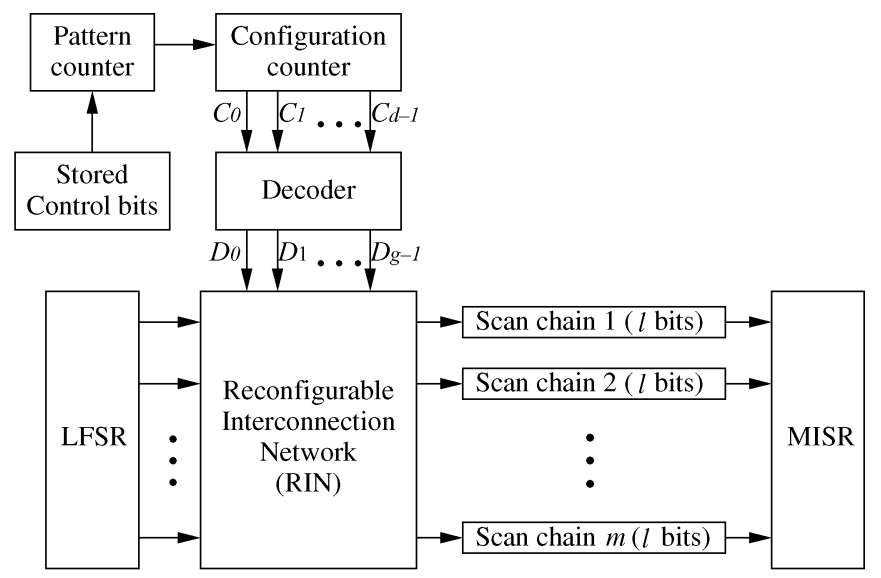

( a )

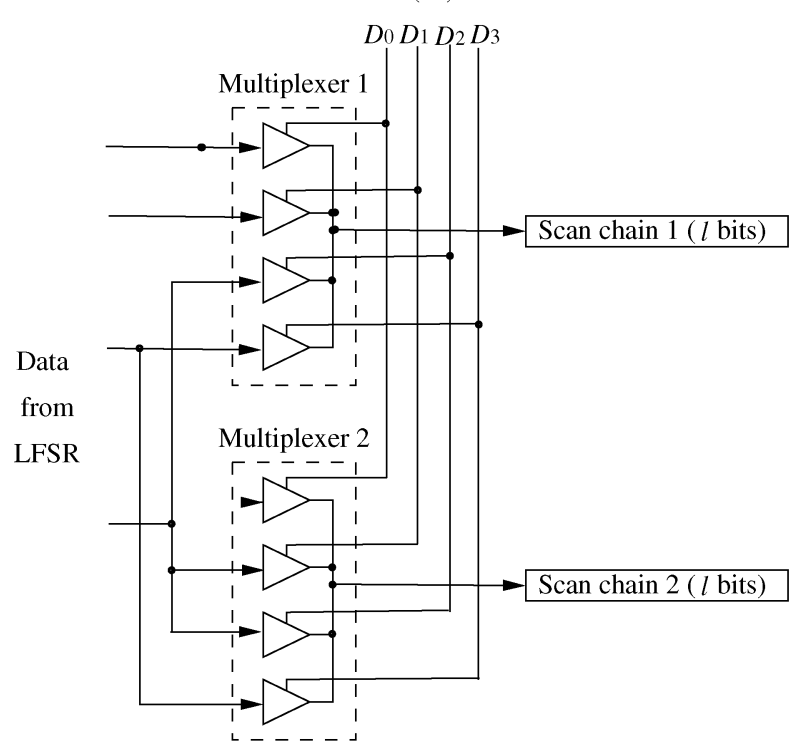

(b)

Fig. 2. (a) Proposed logic BIST architecture. (b) RIN for $m=2$ and $g=4$.

at the output of the multiplexer. Each input $I_{i}$ of a multiplexer is connected to the input of a tristate buffer, which is controlled by the corresponding control signal. While the number of multiplexers can be at most equal to the number of scan chains, in practice, it is sometimes smaller than the number of scan chains because not all scan chains need to be driven by different LFSR cells. The number of tristate gates in each multiplexer is at most equal either to the number of configurations or to the number of LFSR cells, whichever is smaller. Once again, in practice, the actual number of tristate gates is smaller than this upper limit.

We next describe the test-application procedure during a BIST session. First, the configuration counter is reset to the all-0 pattern, and the pattern counter is loaded with the binary value corresponding to the number of patterns that must be applied to the CUT in the first configuration. The pattern counter is decremented each time a test pattern is applied to the CUT. When the content of the pattern counter become zero, it is loaded with the number of patterns for the second configuration and it triggers the configuration counter, which is incremented. This leads to a corresponding change in the outputs of the decoder, and the RIN is reconfigured appropriately. This process

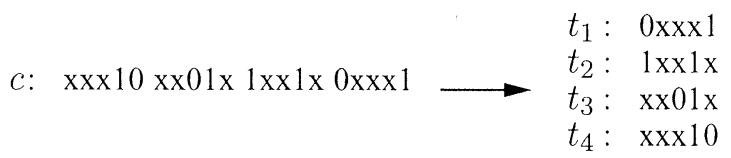

Fig. 3. Illustration of converting a test cube to multiple scan-chain format $(m=4, l=5)$.

continues until the configuration counter passes through all $g$ configurations. The total number of test patterns applied to the CUT is therefore $\sum_{i=1}^{g} n_{i}$, where $n_{i}$ is the number of patterns corresponding to configuration $i, 1 \leq i \leq g$. The BIST design procedure described next is tailored to embed a given set of deterministic test cubes in the sequence of $\sum_{i=1}^{g} n_{i}$ patterns.

During test application, pseudorandom patterns that do not match any deterministic test cube are also applied to the CUT. These pseudorandom patterns can potentially detect nonmodeled faults. However, these patterns increase the testing time. A parameter called MaxSkipPatterns, which is defined as the largest number of pseudorandom patterns that are allowed between the matching of two deterministic cubes, is used in the design procedure to limit the testing time. We first need to determine for each configuration, the number of patterns as well as the interconnections between the LFSR outputs and the scan chains. We use the simulation procedure described next to solve this problem.

We start with an LFSR of length $L$, a predetermined seed, and a known characteristic polynomial. Let $T_{D}=\left\{c_{1}, c_{2}, \ldots, c_{n}\right\}$ be the set of deterministic test cubes that must be applied to the CUT. The set $T_{D}$ can either target all the single stuck-at faults in the circuit, or only the hard faults that cannot be detected by a small number of pseudorandom patterns. As illustrated in Fig. 3, each deterministic test cube $c$ in the test set is converted into the multiple scan-chain format as a set of $m l$-bit vectors $\left\{t_{1}, t_{2}, \ldots, t_{m}\right\}$, where $m$ is the number of scan chains and $l$ is the length of each scan chain. The bits in a test cube are ordered such that the least significant bit is first shifted into the scan chain. We use Conn ${ }_{j}^{(i)}$ to denote the set of LFSR taps that are connected to the scan chain $j$ in configuration $i$, where $i=1,2, \ldots, g, j=1,2, \ldots, m$. The steps of the simulation procedure are as follows.

1) Set $i=1$.

2) Set $\operatorname{Conn}_{j}^{(i)}=\{1,2, \ldots, L\}$ for $j=1,2, \ldots, m$, i.e., initially, each scan chain can be connected to any tap of the LFSR.

3) Driving the LFSR for the next $l$ clock cycles, we obtain the output of the LFSR as a set of $L l$-bit vectors $\left\{O_{k} \mid k=\right.$ $1,2, \ldots, L\}$, where vector $O_{k}$ is the output stream of the $k$ th flip-flop of the LFSR for the $l$ clock cycles.

4) Find a test cube $c^{*}$ in $T_{D}$ that is compatible with the outputs of the LFSR under the current connection configuration $\operatorname{Conn}_{j}^{(i)}$, i.e., for all $j=1, \ldots, m$, there exists $k \in \mathrm{Conn}_{j}^{(i)}$ such that $t_{j}^{*}$ is compatible with $O_{k}$, where $c^{*}$ has already been reformatted for $m$ scan chains as a set of vector $\left\{t_{1}^{*}, t_{2}^{*}, \ldots, t_{m}^{*}\right\}$. (A vector $u_{1}, u_{2}, \ldots, u_{r}$ and a vector $v_{1}, v_{2}, \ldots, v_{r}$ are mutually compatible if for any $i$, $1 \leq i \leq r$, one of the following holds: 1) $u_{i}=v_{i}$ if they 


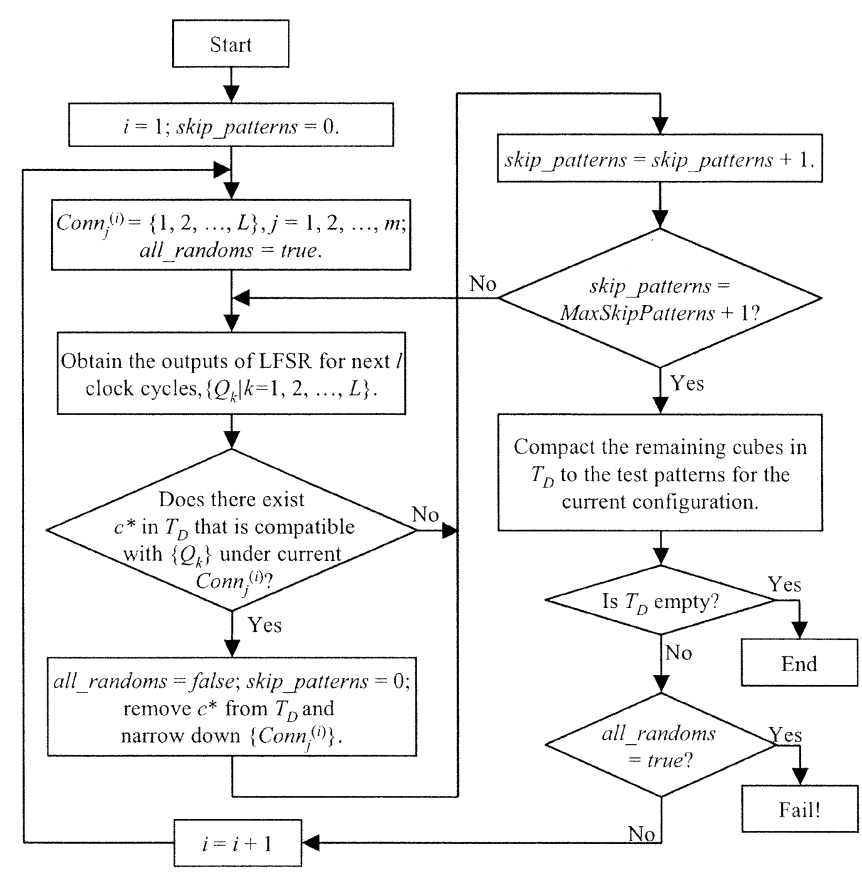

Fig. 4. Flowchart illustrating the simulation procedure.

are both care bits; 2) $u_{i}$ is a don't-care bit; and 3) $v_{i}$ is a don't-care bit.)

5) If no test cube is found in Step 4, go to Step 6 directly. Otherwise, remove the test cube $c^{*}$ found in Step 4 from $T_{D}$, and narrow down the connection configuration as follows. For each $j=1,2, \ldots, m$, let $\mathbf{U} \subset \operatorname{Conn}_{j}^{(i)}$ such that for any $k \in \mathbf{U}, O_{k}$ is not compatible with $t_{j}^{*}$. Then set $\mathrm{Conn}_{j}^{(i)}=\mathrm{Conn}_{j}^{(i)}-\mathbf{U}$.

6) If in the previous MaxSkipPatterns +1 iterations, at least one test cube is found in Step 4, then go to Step 3. Otherwise, the simulation for the current configuration is concluded. The patterns that are applied to the circuit under this configuration are those that are obtained in Step 3.

7) Match the remaining cubes in $T_{D}$ to the test patterns for the current configuration, i.e., if any test vector in $T_{D}$ is compatible with any pattern for the current configuration, remove it from $T_{D}$.

8) If no pseudorandom pattern for the current configuration is compatible with a test cube, the procedure fails and exits. Otherwise, increase $i$ by 1 , and go to Step 2 to begin the iteration for the next configuration until $T_{D}$ is empty.

Fig. 4 shows a flowchart corresponding to the above procedure, where the variable skip_patterns is used to record the number of continuous patterns that are not compatible with any deterministic test cube, and all_randoms is used to indicate if all the patterns for the current configuration are pseudorandom patterns.

An example of the simulation procedure is illustrated in Fig. 5. A four-bit autonomous LFSR with characteristic polynomial $x^{4}+x+1$ is used to generate the pseudorandom patterns. There are four scan chains and the length of each scan chain is four bits. The parameter MaxSkipPatterns is set to 1 . The output of the LFSR is divided into patterns $p_{i}$,

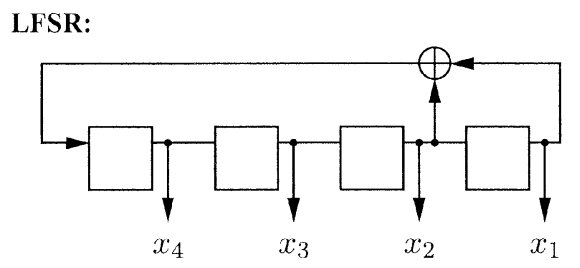

Output of LFSR:

$$
\begin{array}{ccccccccc} 
& \ldots & p_{6} & p_{5} & p_{4} & p_{3} & p_{2} & p_{1} \\
x_{1}: & \ldots & 1100 & 1000 & 1111 & 0101 & 1001 & 0001 \\
x_{2}: & \ldots & 0110 & 0100 & 0111 & 1010 & 1100 & 1000 \\
x_{3}: & \ldots & 1011 & 0010 & 0011 & 1101 & 0110 & 0100 \\
x_{4} & : & \ldots & 0101 & 1001 & 0001 & 1110 & 1011 & 0010
\end{array}
$$

\begin{tabular}{|c|c|c|c|}
\hline \multicolumn{2}{|l|}{ Init) } & a) $p_{1}: c_{1}$ & b) $p_{2}: c_{3}$ \\
\hline \multicolumn{2}{|c|}{$\operatorname{Conn}_{1}^{(1)}:(1,2,3,4)$} & $(1,4)$ & (4) \\
\hline \multicolumn{2}{|c|}{$\operatorname{Conn}_{2}^{(1)}:(1,2,3,4)$} & (2) & (2) \\
\hline \multicolumn{2}{|c|}{$\operatorname{Conn}_{3}^{(1)}:(1,2,3,4)$} & (2) & (2) \\
\hline \multicolumn{2}{|c|}{$\operatorname{Conn}_{4}^{(1)}:(1,2,3,4)$} & $(1,2,4)$ & $(1,4)$ \\
\hline $\begin{array}{l}\text { c) } p_{3}: \text { none } \\
\text { (4) }\end{array}$ & d) $p_{4}: c_{2}$ & $\begin{array}{l}\text { e) } p_{5}, p_{6}: \text { none } \\
\text { (4) }\end{array}$ & f) $\begin{array}{l}p_{2}: c_{4} \\
\text { (4) }\end{array}$ \\
\hline (2) & (2) & (2) & (2) \\
\hline (2) & (2) & (2) & (2) \\
\hline$(1,4)$ & (1) & (1) & (1) \\
\hline
\end{tabular}

Test cubes:

$\begin{array}{cccc}c_{1} & c_{2} & c_{3} & c_{4} \\ 00 \mathrm{xx} & 0 \mathrm{xxx} & \mathrm{xx} 11 & \mathrm{xx} 11 \\ 1 \mathrm{xx} 0 & \mathrm{xx} 1 \mathrm{x} & \mathrm{x} 10 \mathrm{x} & 1 \mathrm{xxx} \\ 10 \mathrm{xx} & 01 \mathrm{xx} & \mathrm{x} 1 \mathrm{x} 0 & 01 \mathrm{xx} \\ \mathrm{x} 0 \mathrm{xx} & 11 \mathrm{xx} & 10 \mathrm{xx} & \mathrm{x} 001\end{array}$

Determination of connections:

Fig. 5. Illustration of the simulation procedure.

$i=1,2, \ldots$. Each pattern consists of four four-bit vectors. The procedure that determines the connections is shown as Steps Init to $\mathrm{f}$. Step Init is the initialization step in which all the connections $\operatorname{Conn}_{j}^{(1)}, j=1,2,3,4$ are set to $\{1,2,3,4\}$. In Step a, the first pattern $p_{1}$ is matched with the test cube $c_{1}$, and the connections are shown for each scan chain: Scan chain 1 can be connected to $x_{1}$ or $x_{4}$, both Scan chains 2 and 3 can only be connected to $x_{2}$, Scan chain 4 can be connected to $x_{1}, x_{2}$, or $x_{4}$. In Step c, none of the cubes is compatible with $p_{3}$. When neither $p_{5}$ nor $p_{6}$ matches any cubes in Step e, the iterations for the current configuration are terminated. The patterns that are applied to the CUT in this configuration are $p_{1}, p_{2}, \ldots, p_{6}$. We then compare the remaining cube $c_{4}$ with the six patterns and find that it is compatible with $p_{2}$. So, $c_{4}$ is also covered by the test patterns for the current configuration. Thus, the connections for this configuration are: Scan chain 1 is connected to $x_{4}$, both Scan chains 2 and 3 are connected to $x_{2}$, Scan chain 4 is connected to $x_{1}$. Since $p_{5}$ and $p_{6}$ are not compatible with any deterministic cubes, the number of patterns for this configuration is set to four. If there are test cubes remaining to be matched, the iteration for the next configuration starts from $p_{5}$. 


\section{Probabilistic Analysis of TeST-Set EMbedDing}

In the test set embedding technique described in Section III, the number of configurations directly determines the hardware overhead for the RIN as well as the storage requirement. In this section, we use probabilistic analysis to determine the average number of configurations for a test set with a given fraction of care bits. This analysis helps us to estimate the number of configurations for test set embedding, without having to simulate the LFSR and check for compatibilities. We use the terminology introduced in Section III, and assume that the care bits are uniformly distributed in the test set.

Let $T_{D}=\left\{c_{1}, c_{2}, \ldots, c_{n}\right\}$ be the set of deterministic test cubes that must be applied to the CUT. Suppose that each deterministic test cube $c$ in the test set is converted to the multiple scan-chain format as a set of $m l$-bit vectors $\left\{t_{1}, t_{2}, \ldots, t_{m}\right\}$, where $m$ is the number of scan chains and $l$ is the length of each scan chain. Driving the $L$-bit LFSR for $l$ clock cycles, we obtain the output of the LFSR as a set of $L l$-bit vectors $\mathbf{O}=\left\{O_{k} \mid k=1,2, \ldots, L\right\}$, where vector $O_{k}$ is the output stream of the $k$ th flip-flop of the LFSR for the $l$ clock cycles. We also obtain $N$ LFSR output sets $\left\{\mathbf{O}_{1}, \mathbf{O}_{2}, \ldots, \mathbf{O}_{N}\right\}$ by driving the LFSR for $N l$ clock cycles in each configuration. In other words, $N$ is the number of test patterns provided by the LFSR in a single configuration.

Let $p$ be the probability that any given bit in the test set is a care bit, i.e., it is specified as either 0 or 1 . Since an LFSR outputs 0 s and $1 \mathrm{~s}$ with equal probability, the probability that any bit of the test set is compatible with an output bit of the LFSR is simply $(1-p)+p / 2=1-p / 2$. Let $\mathcal{E}_{1}$ denote the event that $t_{i}$ is compatible with $O_{k}$, where $1 \leq i \leq m$ and $1 \leq k \leq L$. The probability $P\left[\mathcal{E}_{1}\right]$ of event $\mathcal{E}_{1}$ is simply $(1-p / 2)^{l}$.

Let $\mathcal{E}_{2}$ denote the event that $t_{i}$ is compatible with $\mathbf{O}_{j}$, where $1 \leq i \leq m$ and $1 \leq j \leq N$. It can be easily seen that $t_{i}$ is compatible with $\mathbf{O}_{j}$ if it is compatible with at least one vector in the corresponding LFSR output set $\left\{O_{k} \mid k=1,2, \ldots, L\right\}$. Therefore, the probability of event $\mathcal{E}_{2}$ is given by

$$
\begin{aligned}
p_{2} & =P\left[\mathcal{E}_{2}\right] \\
& =1-\left(1-\left(1-\frac{p}{2}\right)^{l}\right)^{L} .
\end{aligned}
$$

Next, let $\mathcal{E}_{3}$ denote the event that a test cube $c \in T_{D}$ is compatible with $\mathbf{O}_{j}, 1 \leq j \leq N$. This implies that each of the $m$ vectors derived from $c$ is compatible with $\mathbf{O}_{j}$, therefore

$$
\begin{aligned}
p_{3} & =P\left[\mathcal{E}_{3}\right] \\
& =\left(1-\left(1-\left(1-\frac{p}{2}\right)^{l}\right)^{L}\right)^{m} .
\end{aligned}
$$

Let $\mathcal{E}_{4}$ denote the event that a given test cube $c \in T_{D}$ is compatible with at least one LFSR output set among the $N$ elements $\left\{\mathbf{O}_{1}, \mathbf{O}_{2}, \ldots, \mathbf{O}_{N}\right\}$. It can be easily seen that

$$
\begin{aligned}
p_{4} & =P\left[\mathcal{E}_{4}\right] \\
& =1-\left(1-p_{3}\right)^{N} .
\end{aligned}
$$

We next determine the probability $p_{1 N}$ that at least one test cube in $T_{D}$ is compatible with the $N$ LFSR output sets

$$
p_{1 N}=1-\left(1-p_{3}\right)^{N n} .
$$

This implies that $q_{0 N}$, the probability that no test cube in $T_{D}$ is covered by the $N$ LFSR output sets, is simply $\left(1-p_{3}\right)^{N n}$.

Next, we consider the covering of two test cubes with $N$ LFSR output vector sets in the same configuration. Assuming that test cube $c_{1}$ contains $\left\{t_{11}, t_{12}, \ldots, t_{1 m}\right\}, c_{2}$ contains $\left\{t_{21}, t_{22}, \ldots, t_{2 m}\right\}, \mathbf{O}_{1}=\left\{O_{1 k} \mid k=1,2, \ldots, L\right\}$, and $\mathbf{O}_{2}=\left\{O_{2 k} \mid k=1,2, \ldots, L\right\}$, we define the following additional events:

1) $\mathcal{E}_{5}: t_{1 i}$ is compatible with $O_{1 k}$ and $t_{2 i}$ is compatible with $\mathrm{O}_{2 k}$

2) $\mathcal{E}_{6}: t_{1 i}$ is compatible with $\mathbf{O}_{1}$ and $t_{2 i}$ is compatible with $\mathrm{O}_{2}$

3) $\mathcal{E}_{7}: c_{1}$ is compatible with $\mathbf{O}_{1}$ and $c_{2}$ is compatible with $\mathrm{O}_{2}$

4) $\mathcal{E}_{8}: c_{1}$ and $c_{2}$ are compatible with at least one pair of LFSR output vector sets in the $N$ sets $\left\{\mathbf{O}_{1}, \mathbf{O}_{2}, \ldots, \mathbf{O}_{N}\right\}$.

The probabilities associated with the above events are as follows:

$$
\begin{aligned}
P\left[\mathcal{E}_{5}\right] & =\left(1-\frac{p}{2}\right)^{2 l} \\
P\left[\mathcal{E}_{6}\right] & =1-\left(1-\left(1-\frac{p}{2}\right)^{2 l}\right)^{L} \\
p_{7} & =P\left[\mathcal{E}_{7}\right] \\
& =\left(1-\left(1-\left(1-\left(\frac{p}{2}\right)\right)^{2 l}\right)^{L}\right)^{m} \\
P\left[\mathcal{E}_{8}\right] & =1-\left(1-p_{7}\right)^{\left(\begin{array}{c}
N \\
2
\end{array}\right) .}
\end{aligned}
$$

Let $p_{2 N}$ be the probability that at least two test cubes in $T_{D}$ are covered by the $N$ LFSR output vector sets. It therefore follows that:

$$
p_{2 N}=1-\left(1-p_{7}\right)\left(\begin{array}{c}
N \\
2
\end{array}\right)\left(\begin{array}{l}
n \\
2
\end{array}\right) .
$$

Similarly, let $p_{x}$ be the probability that $x$ test cubes are compatible with $x$ given LFSR output vector sets. It can be easily seen that

$$
p_{x}=\left(1-\left(1-\left(1-\left(\frac{p}{2}\right)\right)^{\mathrm{xl}}\right)^{L}\right)^{m}
$$

and $p_{\mathrm{xN}}$, the probability that at least $x$ test cubes in $T_{D}$ are covered by the $N$ LFSR output vector sets, is given by

$$
p_{\mathrm{XN}}=1-\left(1-p_{x}\right)^{\left(\begin{array}{l}
N \\
x
\end{array}\right)\left(\begin{array}{l}
n \\
x
\end{array}\right)} \text {. }
$$

From the formulas for $p_{x N}$ and $p_{(x+1) N}$, we can derive the probability $q_{\mathrm{xn}}$ that the $N$ LFSR output vector sets can cover exact $x$ test cubes

$$
q_{\mathrm{xn}}=p_{\mathrm{xN}}-p_{(x+1) N}
$$

where $x=1,2, \ldots, \min (n, N)$. Hence, the average number of 


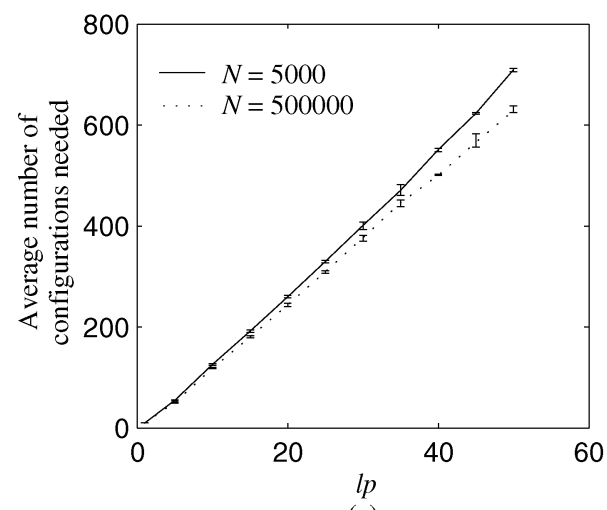

(a)

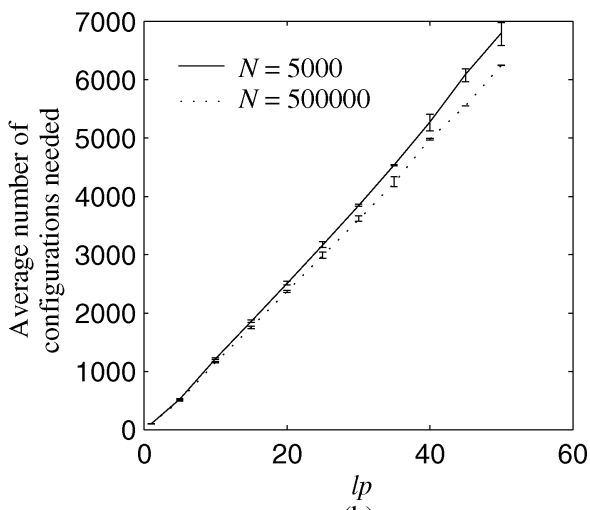

(b)

Fig. 6. Average number of configurations needed versus $l p$ for (a) $n=100$ and (b) $n=1000$.

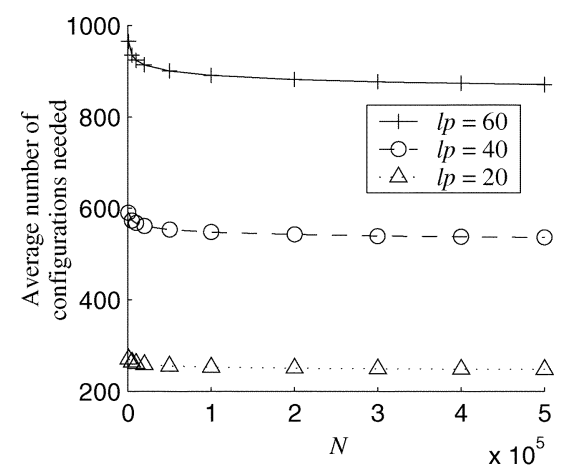

(a)

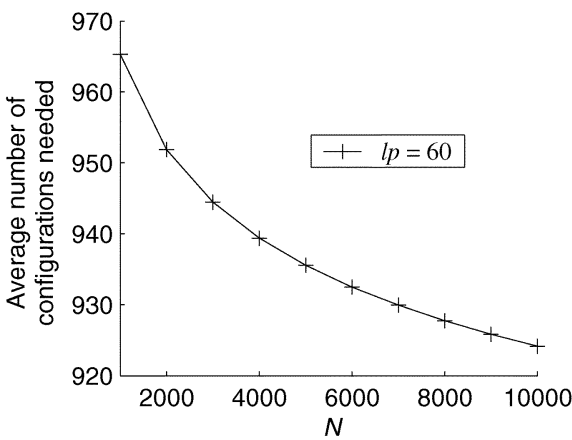

(c)

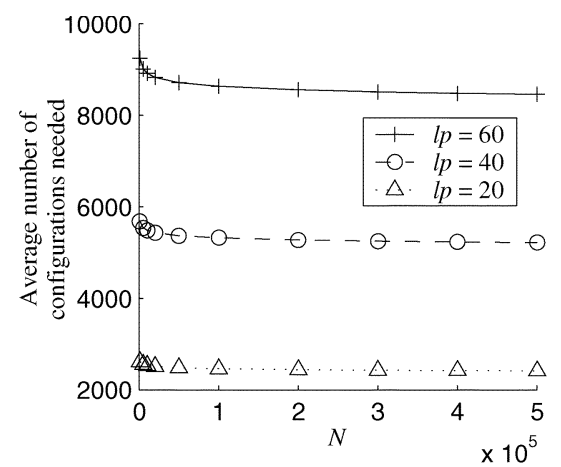

(b)

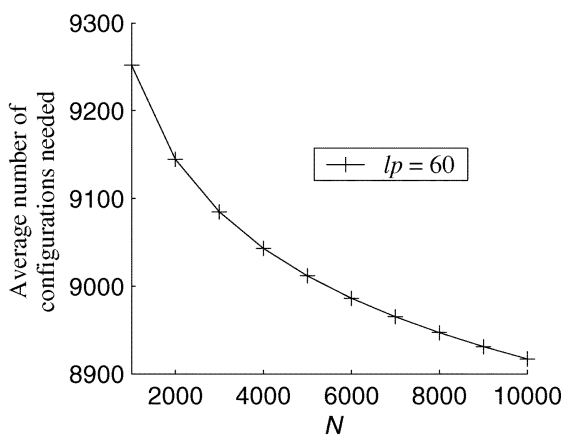

(d)

Fig. 7. Average number of configurations needed versus $N$ for (a) $n=100$, (b) $n=1000$, (c) $n=100,1000 \leq N \leq 10000$, and (d) $n=1000$, $1000 \leq N \leq 10000$.

test cubes that the $N$ LFSR output vector sets can cover is simply $z=\sum_{i=0}^{\min (n, N)} i q_{\text {in }}$, and the average number of configurations needed to embed the test set $T_{D}$ is, therefore, $n / z$.

Fig. 6(a) and (b) show the average number of configurations needed to embed the test set with $n=100$ and $n=1000$, respectively. Since the number of specified bits per scan chain for a test cube affects the number of configurations, we also vary $l p$, the average number of specified bits per scan chain for a test cube, from 1 to 50 and compute the results for two different values of $N$. For each value of $l p$, ten pairs of $(l, p)$ values corresponding to $p=0.01,0.02, \ldots, 0.10$ are used to compute the average number of configurations needed. The graphs are drawn by joining points corresponding to the mean obtained over the ten values of $p$. The minimum and the maximum values are shown in the figures as a vertical bar for each point. For determining the average number of configurations, we assumed the number of scan chains $m=32$ and the length of the LFSR $L=64$. The average number of configurations needed tends to increase linearly with $l p$. For larger values of $l p$, the number of patterns generated in each configuration $N$ affects the number of configurations; this dependence is less pronounced for smaller values of $l p$. The effect of $N$ on the number of configurations is shown in Fig. 7.

In Table XII of Section VI, we list the number of configurations predicted by the analysis. The analytical results closely match the experimental results. The match is less pronounced for other sets of experiments; nevertheless, the analysis provides a useful prediction for the effectiveness of the proposed method. 


\section{DeClustering the CARE Bits}

The simulation procedure to determine the number of patterns and the connections for each configuration can sometimes fail to embed the test cubes in the LFSR sequence. This can happen if MaxSkipPatterns is too small, or the test cubes are hard to match with the outputs of the LFSR. During our experiments, we found that it was very difficult to embed the test cubes for the 38417 benchmark circuit. On closer inspection, we found that the care bits in some of the test cubes for s38417 are highly clustered, even though the percentage of care bits in $T_{D}$ is small. When these test cubes are converted into a multiple-scan-chain format, most of the vectors contain very few care bits, but a few vectors contain a large number of care bits. These vectors with many care bits are hard to embed in the output sequence of the LFSR.

In order to embed test cubes with highly clustered care bits, we propose two declustering strategies. The first is to reorganize the scan chains such that the care bits can be scattered across many scan chains, and each scan chain contains only a few care bits. Another strategy is based on the use of additional logic to interleave the data that are shifted into the different scan chains. The first strategy requires reorganization of the scan chains, but it does not require extra hardware overhead. Care needs to be taken in scan-chain redesign to avoid timing closure problems. The interleaving method does not modify the scan chains, but it requires additional hardware and control mechanisms.

The method of reorganization of scan chains is illustrated in Fig. 8. As shown in the figure, before the reorganization, all the care bits of the given test cube are grouped in the second vector, which is hard to match with the output of LFSR. After the reorganization, the care bits are scattered across all the vectors, and the largest number of care bits in a vector is only two. This greatly increases the probability that this vector can be matched to an output pattern of the LFSR. Note that the concept of reorganization of scan chains is also used in [11]. However, the reorganization used in [11] changes the scan-chain structure and makes it unsuitable for response capture-a separate solution is needed in [11] to circumvent this problem. In our approach, the basic structure of the scan chains is maintained and the usual scan-test procedure of pattern shift-in, response capture, and shift-out can be used.

The scan cells in the CUT can be indexed as $c_{i, j}$, $i=0,1, \ldots, m-1, j=0,1, \ldots, l-1$, where $m$ is the number of scan chains and $l$ is the length of a scan chain. Note that we start the indices from 0 to facilitate the description of the scan-chain reorganization procedure. The $i$ th scan chain consists of the $l$ scan cells $c_{i, j}, j=0,1, \ldots, l-1$. We use $c_{i, j}^{*}$ to denote the reorganized scan cells, in which the $i$ th scan chain consists of the $l$ scan cells $c_{i, j}^{*}, j=0,1, \ldots, l-1$. For each $j=0,1, \ldots, l-1$, the $m$ cells $c_{0, j}, c_{1, j}, \ldots, c_{m-1, j}$ constitute a vertical vector. The reorganized scan cell structure is obtained by rotating each such vertical vector upwards by $d$ positions, where $d=j \bmod m$, i.e., $c_{i, j}^{*}=c_{k, j}$, where $k$ is given by $k=(i+d) \bmod m$.

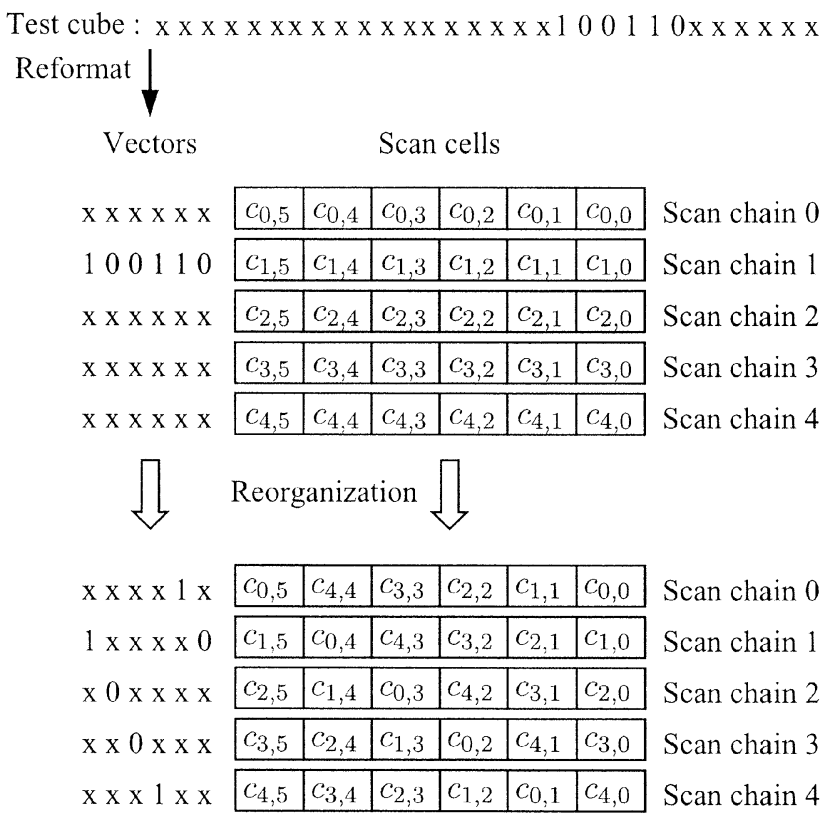

Fig. 8. Illustration of the reorganization of scan chains.

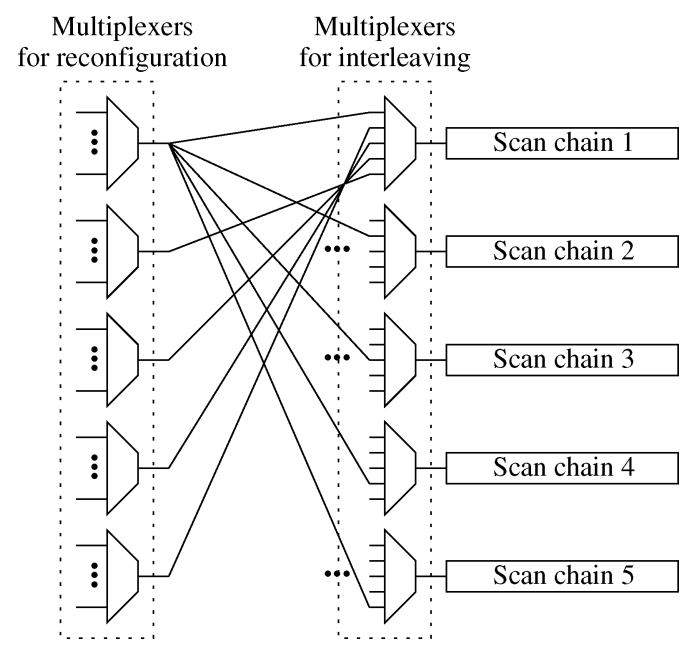

Fig. 9. Illustration of interleaving of the inputs of scan chains.

An alternative method for declustering, based on the interleaving of the inputs to the scan chains, is shown in Fig. 9. We insert an extra stage of multiplexers between the outputs of the RIN and the inputs of the scan chains. From the perspective of the RIN, the logic that follows it, i.e., the combination of the multiplexers for interleaving and the scan chains, is simply a reorganized scan chain with an appropriate arrangement of the connections between the two stages of multiplexers. For a CUT with $m$ scan chains, $m$ multiplexers are used for reconfiguration, and $m$ multiplexers are inserted for interleaving. Each of the multiplexers used for interleaving has $m$ inputs, which are selected in ascending order during the shifting in of a test pattern, i.e., the first input is selected for the first scan-clock cycle, the second input is selected for the second scan clock cycle, and so on. After the $m$ th input is selected, the procedure is repeated 
with the first input. We use $A_{i}$ to denote the output the $i$ th multiplexers for reconfiguration and $B_{i, j}$ to denote the $j$ th input of the $i$ th multiplexers for interleaving, where $i, j=1,2, \ldots, m$. The interleaving is carried out by connecting the inputs of the multiplexers for interleaving with the outputs of multiplexers for reconfiguration such that

$$
B_{i, j}= \begin{cases}A_{i-j+1,} & \text { if } i \geq j \\ A_{i-j+1+m,}, & \text { if } i<j\end{cases}
$$

In order to control the multiplexers for interleaving, an architecture similar to the control logic for the RIN can be used. However, for the interleaving, we do not need any storage and the pattern counter. A bit counter counting up to $m-1$, (where $m$ is the number of scan chains) is used to replace the configuration counter. The bit counter is reset to 0 at the start of the shifting in of each pattern, and it returns to 0 after counting to $m-1$.

Consider the test cube shown in Fig. 8. After adding the second stage of multiplexers and connecting the inputs of the multiplexers for interleaving with the outputs of the multiplexers for reconfiguration, as shown in Fig. 9 (only the connections related to the first RIN multiplexer are shown for clarity), the output of the first multiplexer for reconfiguration should match with "xxxx1x," the same string as that in scan-cell reorganization method. Note that the above reorganization and interleaving procedures yield the same set of test cubes.

\section{EXPERIMENTAL RESULTS AND DISCUSSION}

In this section, we present experimental results for the seven largest ISCAS' 89 circuits and for test cubes for two production circuits from IBM. We use three sets of test cubes $T_{D}$ for the large ISCAS' 89 circuits. The first set of test cubes are obtained from the Mintest ATPG program [10] without dynamic compaction, and by targeting all the irredundant single stuck-at faults. The other two test sets are the same test sets used in [11]. The second set of the test cubes are obtained without an initial pseudorandom pattern application, and they target all irredundant faults. The third set of the test cubes for the random-pattern-resistant faults is obtained after 10000 pseudorandom patterns are applied to the circuits. We carried out experiments for each of the ISCAS' 89 circuits with 32 scan chains, and also ran experiments for the larger circuits with 64 scan chains. In all of these experiments, we used a 64-bit primitive-polynomial LFSR with a fixed randomly-generated seed as the pseudorandom pattern generator. For simplicity of presentation, we assume that the circuits have balanced scan chains. When the scan chains are unbalanced, we can view them as being balanced through the addition of dummy scan cells.

Tables I and II present the results on test set embedding where $T_{D}$ is obtained using the Mintest program. We use a value of 5000 for the MaxSkipPatterns parameter for this set of experiments. The fifth column shows the total number of configurations needed to embed $T_{D}$. The total number of patterns applied to the circuit is listed in the sixth column. The testing time in clock cycles is obtained as the product of the total number of patterns and $(l+1)$, where $l$ is the length of scan chains. We implemented the RIN architecture containing the multiplexers for reconfiguration, the decoder and the configuration counter using the 1si_10k library of Synopsys design compiler to estimate the hardware overhead. Using the wire load model for the 1si_10k library, we designate the normalized area for a unitlength of wire to be 0.2 (assuming that the area of an inverter is 1 unit) to take into account the area of interconnects. The hardware area for each of the ISCAS' 89 benchmark circuits is obtained in the same way. The percentage hardware overhead is obtained from the ratio of the area of BIST hardware to the area of the CUT. The pattern counter is not included in the calculation of the BIST hardware overhead because it is required for any scan-BIST scheme. The encoding efficiency shown in the tables is the ratio of the number of care bits in the test set to the amount of storage needed. The CPU times, listed in the last column, correspond to the simulation time required to embed the deterministic test cubes using a Sun Blade 1000 workstation with a 750-MHz UltraSPARC-III CPU and 1 GB of memory. The results in Table I show that only a small number of control bits (at most a few hundred) are required for test set embedding. The hardware overhead of the RIN, the decoder, and the configuration counter are also very small, less then $7 \%$ for five circuits, and only $5.34 \%$ on average. Similar results are presented in Table II.

As indicated in Tables I and II, we were unable to embed the test cubes fbits in these test cubes are highly clustered. As a result, it is difficult to match these cubes to the patterns obtained from the LFSR. We therefore considered scan-chain reorganization to obtain experimental results for s38417. Tables III and IV show the result obtained with scan-chain reorganization for the seven largest benchmark circuits with 32 and 64 scan chains, respectively.

Tables V and VI present experimental results on the embedding of test cubes from [11] targeting all faults, without scan-chain reorganization and with scan-chain reorganization, respectively. In these two sets of experiments, we set the parameter MaxSkipPatterns to 10000 and set the number of scan chains in each circuit to 32. As indicated in Table V, we were unable to embed the test cubes of s38417 due to a high degree of clustering of its care bits. This problem was addressed using scan-chain reorganization; the results are shown in Table VI. Scan-chain reorganization for this set of test cubes reduces the number of configurations, and hence the storage and the hardware overhead for all circuits except s5378. Similar results are shown in Tables VII and VIII, with 64 scan chains assumed for each CUT.

Tables IX and X present experimental results obtained using the test cubes from [11] that target random-pattern-resistant faults. We assume that, as in other mixed-mode BIST schemes, the RIN is bypassed using multiplexers for the first 10000 pseudorandom patterns. We considered scan-chain reorganization for these experiments. As expected, compared with the results for test sets targeting all faults, the total number of patterns here is much smaller. Thus the testing time is also much less than in Table VII. The average storage requirement for the seven circuits is reduced from 900 to 534 bits. 
TABLE I

Experimental Results for Mintest Test Sets Targeting All Faults (Assuming 32 Scan Chains for Each Circuit)

\begin{tabular}{c|c|c|c|c|c|c|c|c|c|c}
\hline \hline & $\begin{array}{c}\text { No. of } \\
\text { test } \\
\text { Circuit }\end{array}$ & $\begin{array}{c}\text { No. of } \\
\text { scan } \\
\text { cells }\end{array}$ & $\begin{array}{c}\text { Length } \\
\text { of scan } \\
\text { chain }\end{array}$ & $\begin{array}{c}\text { No. of } \\
\text { configurations }\end{array}$ & $\begin{array}{c}\text { BIST } \\
\text { patterns }\end{array}$ & $\begin{array}{c}\text { Testing } \\
\text { time (clock } \\
\text { cycles) }\end{array}$ & $\begin{array}{c}\text { Hardware } \\
\text { overhead } \\
\text { (percentage) }\end{array}$ & $\begin{array}{c}\text { Storage } \\
\text { requirement } \\
\text { (bits) }\end{array}$ & $\begin{array}{c}\text { Encoding } \\
\text { efficiency }\end{array}$ & $\begin{array}{c}\text { CPU } \\
\text { time }\end{array}$ \\
\hline s5378 & 1458 & 214 & 7 & 9 & 157184 & 1257472 & $6.49 \%$ & 162 & 81.44 & $2 \mathrm{~m}$ \\
\hline s9234 & 1928 & 247 & 8 & 34 & 363551 & 3271959 & $15.31 \%$ & 646 & 39.57 & $3 \mathrm{~m}$ \\
\hline $\mathrm{s} 13207$ & 3237 & 700 & 22 & 9 & 322526 & 7418098 & $2.69 \%$ & 171 & 157.02 & $5 \mathrm{~m}$ \\
\hline $\mathrm{s} 15850$ & 3920 & 611 & 20 & 24 & 379377 & 7966917 & $5.81 \%$ & 456 & 67.02 & $7 \mathrm{~m}$ \\
\hline $\mathrm{s} 35932$ & 10810 & 1763 & 56 & 4 & 19756 & 1126092 & $0.55 \%$ & 60 & 771.18 & $3 \mathrm{~m}$ \\
\hline $\mathrm{s} 38417^{*}$ & 10771 & 1664 & 52 & - & - & - & - & - & - & - \\
\hline s38584 & 13468 & 1464 & 46 & 11 & 377804 & 17756788 & $1.19 \%$ & 209 & 441.15 & $16 \mathrm{~m}$ \\
\hline Average & - & - & - & 15 & 270033 & 6466221 & $5.34 \%$ & 284 & 259.56 & $6 \mathrm{~m}$ \\
\hline
\end{tabular}

${ }^{*}$ Care bits are highly clustered hence test cubes could not be embedded with MaxSkipPatterns $=5000$.

TABLE II

EXPERImental Results for Mintest Test Sets TARgeting All Faults (Assuming 64 Scan Chains for Each Circuit)

\begin{tabular}{|c|c|c|c|c|c|c|c|c|c|c|}
\hline Circuit & $\begin{array}{c}\text { No. of } \\
\text { test } \\
\text { cubes }\end{array}$ & $\begin{array}{l}\text { No. of } \\
\text { scan } \\
\text { cells }\end{array}$ & $\begin{array}{l}\text { Length } \\
\text { of scan } \\
\text { chain }\end{array}$ & $\begin{array}{c}\text { No. of } \\
\text { configurations }\end{array}$ & $\begin{array}{l}\text { No. of } \\
\text { BIST } \\
\text { patterns }\end{array}$ & $\begin{array}{c}\text { Testing } \\
\text { time (clock } \\
\text { cycles) }\end{array}$ & $\begin{array}{c}\text { Hardware } \\
\text { overhead } \\
\text { (percentage) }\end{array}$ & $\begin{array}{c}\text { Storage } \\
\text { requirement } \\
\text { (bits) }\end{array}$ & $\begin{array}{l}\text { Encoding } \\
\text { efficiency }\end{array}$ & $\begin{array}{l}\mathrm{CPU} \\
\text { time }\end{array}$ \\
\hline s13207 & 3237 & 700 & 11 & 10 & 114779 & 1377348 & $5.31 \%$ & 170 & 157.95 & $5 \mathrm{~m}$ \\
\hline s 15850 & 3920 & 611 & 10 & 13 & 212027 & 2332297 & $5.98 \%$ & 234 & 130.61 & $10 \mathrm{~m}$ \\
\hline s35932 & 10810 & 1763 & 28 & 5 & 7294 & 211526 & $1.19 \%$ & 65 & 711.86 & $4 \mathrm{~m}$ \\
\hline s38417* & 10771 & 1664 & 26 & - & - & - & - & - & - & - \\
\hline s38584 & 13468 & 1464 & 23 & 8 & 304981 & 7319544 & $1.64 \%$ & 152 & 606.58 & $19 \mathrm{~m}$ \\
\hline Average & - & - & - & 9 & 159770 & 2810179 & $3.53 \%$ & 155 & 401.75 & $10 \mathrm{~m}$ \\
\hline
\end{tabular}

${ }^{*}$ Care bits are highly clustered hence test cubes could not be embedded with MaxSkipPatterns $=5000$.

TABLE III

Experimental Results for Mintest Test Sets Targeting All Faults and With Scan-Cell REORGANIZATION (ASSUMING 32 SCAN CHAINS FOR EACH CIRCUIT)

\begin{tabular}{c|c|c|c|c|c|c|c|c|c|c}
\hline \hline & $\begin{array}{c}\text { No. of } \\
\text { test } \\
\text { Circuit }\end{array}$ & $\begin{array}{c}\text { No. of } \\
\text { scan } \\
\text { cells }\end{array}$ & $\begin{array}{c}\text { Length } \\
\text { of scan } \\
\text { chain }\end{array}$ & $\begin{array}{c}\text { No. of } \\
\text { configurations }\end{array}$ & $\begin{array}{c}\text { BIST } \\
\text { patterns }\end{array}$ & $\begin{array}{c}\text { Testing } \\
\text { time (clock } \\
\text { cycles) }\end{array}$ & $\begin{array}{c}\text { Hardware } \\
\text { overhead } \\
\text { (percentage) }\end{array}$ & $\begin{array}{c}\text { Storage } \\
\text { requirement } \\
\text { (bits) }\end{array}$ & $\begin{array}{c}\text { Encoding } \\
\text { efficiency }\end{array}$ & $\begin{array}{c}\text { CPU } \\
\text { time }\end{array}$ \\
\hline s5378 & 1458 & 214 & 7 & 8 & 67988 & 543904 & $7.68 \%$ & 136 & 97.01 & $2 \mathrm{~m}$ \\
\hline s9234 & 1928 & 247 & 8 & 36 & 135765 & 1221885 & $16.04 \%$ & 648 & 39.44 & $3 \mathrm{~m}$ \\
\hline s13207 & 3237 & 700 & 22 & 9 & 152596 & 3509708 & $2.69 \%$ & 162 & 165.75 & $5 \mathrm{~m}$ \\
\hline s15850 & 3920 & 611 & 20 & 22 & 222336 & 4669056 & $5.38 \%$ & 396 & 77.18 & $5 \mathrm{~m}$ \\
\hline s35932 & 10810 & 1763 & 56 & 5 & 7079 & 403503 & $0.67 \%$ & 65 & 711.86 & $4 \mathrm{~m}$ \\
\hline s38417 & 10771 & 1664 & 52 & 272 & 625273 & 33139469 & $26.39 \%$ & 5440 & 26.14 & $1 \mathrm{~h} 43 \mathrm{~m}$ \\
\hline s38584 & 13468 & 1464 & 46 & 12 & 383009 & 18001423 & $1.29 \%$ & 228 & 404.39 & $14 \mathrm{~m}$ \\
\hline Average & - & - & - & 52 & 227721 & 8784135 & $8.59 \%$ & 1011 & 217.39 & $19 \mathrm{~m}$ \\
\hline
\end{tabular}

In the above set of experiments, we assumed that the information on the different number of patterns for each configuration is stored on-chip. If a fixed number of patterns is applied per configuration, then no storage is required. A tradeoff is that a fixed number of patterns per configuration might increase the number of configurations, and thereby increase the hardware overhead. In the next set of experiments, we limit the number of patterns for each configuration to 1000. As expected, the results in Tables XI and XII show that the hardware overhead increase slightly for each circuit. Nevertheless, an important 
TABLE IV

Experimental Results for Mintest Test Sets Targeting All Faults and With SCAN-Cell REORGANIZATION (ASSUMING 64 SCAN CHAINS FOR EACH CIRCUIT)

\begin{tabular}{c|c|c|c|c|c|c|c|c|c|c}
\hline \hline & $\begin{array}{c}\text { No. of } \\
\text { test } \\
\text { cubes }\end{array}$ & $\begin{array}{c}\text { No. of } \\
\text { scan } \\
\text { cells }\end{array}$ & $\begin{array}{c}\text { Length } \\
\text { of scan } \\
\text { chain }\end{array}$ & $\begin{array}{c}\text { No. of } \\
\text { configurations }\end{array}$ & $\begin{array}{c}\text { No. of } \\
\text { BIST } \\
\text { patterns }\end{array}$ & $\begin{array}{c}\text { Testing } \\
\text { time (clock } \\
\text { cycles) }\end{array}$ & $\begin{array}{c}\text { Hardware } \\
\text { overhead } \\
\text { (percentage) }\end{array}$ & $\begin{array}{c}\text { Storage } \\
\text { requirement } \\
\text { (bits) }\end{array}$ & $\begin{array}{c}\text { Encoding } \\
\text { efficiency }\end{array}$ & $\begin{array}{c}\text { CPU } \\
\text { time }\end{array}$ \\
\hline s13207 & 3237 & 700 & 11 & 11 & 75047 & 900564 & $5.80 \%$ & 187 & 143.59 & $5 \mathrm{~m}$ \\
\hline s15850 & 3920 & 611 & 10 & 11 & 179580 & 1975380 & $5.12 \%$ & 198 & 154.36 & $9 \mathrm{~m}$ \\
\hline $\mathrm{s} 35932$ & 10810 & 1763 & 28 & 6 & 6080 & 176320 & $1.40 \%$ & 78 & 593.22 & $4 \mathrm{~m}$ \\
\hline $\mathrm{s} 38417$ & 10771 & 1664 & 26 & 130 & 616835 & 16654545 & $24.40 \%$ & 2600 & 54.69 & $1 \mathrm{~h} 35 \mathrm{~m}$ \\
\hline s38584 & 13468 & 1464 & 23 & 7 & 291425 & 6994200 & $1.41 \%$ & 133 & 693.23 & $17 \mathrm{~m}$ \\
\hline Average & - & - & - & 33 & 233793 & 5340202 & $7.63 \%$ & 639 & 327.82 & $26 \mathrm{~m}$ \\
\hline
\end{tabular}

TABLE V

EXPerimental Results for TeSt Sets From [11] Targeting All Faults (Assuming 32 SCAN Chains for Each Circuit)

\begin{tabular}{c|c|c|c|c|c|c|c|c|c|c}
\hline \hline Circuit & $\begin{array}{c}\text { No. of } \\
\text { test } \\
\text { cubes }\end{array}$ & $\begin{array}{c}\text { No. of } \\
\text { scan } \\
\text { cells }\end{array}$ & $\begin{array}{c}\text { Length } \\
\text { of scan } \\
\text { chain }\end{array}$ & $\begin{array}{c}\text { No. of } \\
\text { configurations }\end{array}$ & $\begin{array}{c}\text { No. of } \\
\text { BIST } \\
\text { patterns }\end{array}$ & $\begin{array}{c}\text { Testing } \\
\text { time (clock } \\
\text { cycles) }\end{array}$ & $\begin{array}{c}\text { Hardware } \\
\text { overhead } \\
\text { (percentage) }\end{array}$ & $\begin{array}{c}\text { Storage } \\
\text { requirement } \\
\text { (bits) }\end{array}$ & $\begin{array}{c}\text { Encoding } \\
\text { efficiency }\end{array}$ & $\begin{array}{c}\text { CPU } \\
\text { time }\end{array}$ \\
\hline s5378 & 4397 & 214 & 7 & 6 & 289754 & 2318032 & $5.60 \%$ & 114 & 313.81 & $5 \mathrm{~m}$ \\
\hline s9234 & 6475 & 247 & 8 & 57 & 394496 & 3550464 & $24.94 \%$ & 1083 & 72.55 & $16 \mathrm{~m}$ \\
\hline s13207 & 9608 & 700 & 22 & 11 & 580521 & 13351983 & $3.16 \%$ & 220 & 315.13 & $22 \mathrm{~m}$ \\
\hline s15850 & 11330 & 611 & 20 & 32 & 758497 & 15928437 & $7.65 \%$ & 640 & 129.96 & $28 \mathrm{~m}$ \\
\hline s38417* & 30859 & 1664 & 52 & - & - & - & - & - & - & - \\
\hline s38584 & 34493 & 1464 & 46 & 12 & 526555 & 24748085 & $1.29 \%$ & 240 & 822.90 & $27 \mathrm{~m}$ \\
\hline Average & - & - & - & 24 & 509964 & 11979400 & $8.53 \%$ & 459 & 330.87 & $20 \mathrm{~m}$ \\
\hline
\end{tabular}

${ }^{*}$ Care bits are highly clustered hence test cubes could not be embedded with MaxSkipPatterns $=10000$.

TABLE VI

EXPerimental Results for Test Sets From [11] TARgeting All Faults and With SCAN-Cell REORGANIZATION (ASSUMING 32 SCAN CHAINS FOR EACH CIRCUIT)

\begin{tabular}{|c|c|c|c|c|c|c|c|c|c|c|}
\hline Circuit & $\begin{array}{c}\text { No. of } \\
\text { test } \\
\text { cubes }\end{array}$ & $\begin{array}{l}\text { No. of } \\
\text { scan } \\
\text { cells }\end{array}$ & $\begin{array}{l}\text { Length } \\
\text { of scan } \\
\text { chain }\end{array}$ & $\begin{array}{c}\text { No. of } \\
\text { configurations }\end{array}$ & $\begin{array}{c}\text { No. of } \\
\text { BIST } \\
\text { patterns }\end{array}$ & $\begin{array}{c}\text { Testing } \\
\text { time (clock } \\
\text { cycles) }\end{array}$ & $\begin{array}{c}\text { Hardware } \\
\text { overhead } \\
\text { (percentage) }\end{array}$ & $\begin{array}{c}\text { Storage } \\
\text { requirement } \\
\text { (bits) }\end{array}$ & $\begin{array}{l}\text { Encoding } \\
\text { efficiency }\end{array}$ & $\begin{array}{l}\text { CPU } \\
\text { time }\end{array}$ \\
\hline s5378 & 4397 & 214 & 7 & 8 & 250275 & 2002200 & $7.68 \%$ & 144 & 248.43 & $2 m$ \\
\hline s9234 & 6475 & 247 & 8 & 31 & 562133 & 5059197 & $13.80 \%$ & 620 & 126.73 & $7 \mathrm{~m}$ \\
\hline s13207 & 9608 & 700 & 22 & 11 & 297713 & 6847399 & $3.16 \%$ & 209 & 331.72 & $17 \mathrm{~m}$ \\
\hline s15850 & 11330 & 611 & 20 & 18 & 634468 & 13323828 & $4.43 \%$ & 360 & 231.04 & $17 \mathrm{~m}$ \\
\hline s38417 & 30859 & 1664 & 52 & 184 & 1707485 & 90496705 & $17.94 \%$ & 3864 & 75.35 & $1 \mathrm{~h} 51 \mathrm{~m}$ \\
\hline s38584 & 34493 & 1464 & 46 & 10 & 736686 & 34624242 & $1.10 \%$ & 200 & 987.48 & $30 \mathrm{~m}$ \\
\hline Average & - & - & - & 44 & 698126 & 25392262 & $8.02 \%$ & 900 & 333.46 & $31 \mathrm{~m}$ \\
\hline
\end{tabular}

benefit here is that no storage is necessary for control bits. We also note from Table XII that the number of configurations predicted by the analysis of Section IV is close to the experimental values.

In Section III, we highlighted the fact that the number of multiplexers in the RIN is often smaller than the number of scan chains because not all scan chains need to be driven by different
LFSR cells. We also noted that the actual number of tristate gates in each multiplexer is sometimes smaller than its upper limit, which is equal to the smaller of the number of configurations or the number of LFSR cells. Here, we report these numbers for the s5378 benchmark circuit with 32 scan chains. Eleven scan chains are directly connected to the LFSR taps, and only 77 tristate gates are needed for the total of 21 multiplexer 
TABLE VII

EXPERimental Results for Test Sets From [11] Targeting All Faults (Assuming 64 Scan Chains for Each Circuit)

\begin{tabular}{c|c|c|c|c|c|c|c|c|c|c}
\hline \hline & $\begin{array}{c}\text { No. of } \\
\text { test } \\
\text { Circuit }\end{array}$ & $\begin{array}{c}\text { No. of } \\
\text { scan } \\
\text { cells }\end{array}$ & $\begin{array}{c}\text { Length } \\
\text { of scan } \\
\text { chain }\end{array}$ & $\begin{array}{c}\text { No. of } \\
\text { configurations }\end{array}$ & $\begin{array}{c}\text { BIST } \\
\text { patterns }\end{array}$ & $\begin{array}{c}\text { Testing } \\
\text { time (clock } \\
\text { cycles) }\end{array}$ & $\begin{array}{c}\text { Hardware } \\
\text { overhead } \\
\text { (percentage) }\end{array}$ & $\begin{array}{c}\text { Storage } \\
\text { requirement } \\
\text { (bits) }\end{array}$ & $\begin{array}{c}\text { Encoding } \\
\text { efficiency }\end{array}$ & $\begin{array}{c}\text { CPU } \\
\text { time }\end{array}$ \\
\hline s13207 & 9608 & 700 & 11 & 14 & 608383 & 7300596 & $7.27 \%$ & 280 & 247.60 & $23 \mathrm{~m}$ \\
\hline s15850 & 11330 & 611 & 10 & 27 & 776581 & 8542391 & $12.29 \%$ & 540 & 154.03 & $32 \mathrm{~m}$ \\
\hline s38417* & 30859 & 1664 & 26 & - & - & - & - & - & - & - \\
\hline s38584 & 34493 & 1464 & 23 & 10 & 849505 & 20388120 & $2.00 \%$ & 200 & 987.48 & $37 \mathrm{~m}$ \\
\hline Average & - & - & - & 17 & 744823 & 12077036 & $7.19 \%$ & 340 & 463.04 & $31 \mathrm{~m}$ \\
\hline
\end{tabular}

*Care bits are highly clustered hence test cubes could not be embedded with MaxSkipPatterns $=10000$.

TABLE VIII

Experimental Results for Test Sets From [11] TARgeting All Faults and With Scan-Cell REORGANIZATION (ASSUMING 64 SCAN CHAINS FOR EACH CIRCUIT)

\begin{tabular}{c|c|c|c|c|c|c|c|c|c|c}
\hline \hline & $\begin{array}{c}\text { No. of } \\
\text { test } \\
\text { Circuit }\end{array}$ & $\begin{array}{c}\text { No. of } \\
\text { scan } \\
\text { cells }\end{array}$ & $\begin{array}{c}\text { Length } \\
\text { of scan } \\
\text { chain }\end{array}$ & $\begin{array}{c}\text { No. of } \\
\text { configurations }\end{array}$ & $\begin{array}{c}\text { No. of } \\
\text { BIST } \\
\text { patterns }\end{array}$ & $\begin{array}{c}\text { Testing } \\
\text { time (clock } \\
\text { cycles) }\end{array}$ & $\begin{array}{c}\text { Hardware } \\
\text { overhead } \\
\text { (percentage) }\end{array}$ & $\begin{array}{c}\text { Storage } \\
\text { requirement } \\
\text { (bits) }\end{array}$ & $\begin{array}{c}\text { Encoding } \\
\text { efficiency }\end{array}$ & $\begin{array}{c}\text { CPU } \\
\text { time }\end{array}$ \\
\hline s13207 & 9608 & 700 & 11 & 15 & 341543 & 4098516 & $7.76 \%$ & 285 & 243.26 & $20 \mathrm{~m}$ \\
\hline $\mathrm{s} 15850$ & 11330 & 611 & 10 & 14 & 591651 & 6508161 & $6.42 \%$ & 280 & 297.05 & $33 \mathrm{~m}$ \\
\hline $\mathrm{s} 38417$ & 30859 & 1664 & 26 & 110 & 270978 & 7316406 & $20.66 \%$ & 2090 & 139.30 & $2 \mathrm{~h} 3 \mathrm{~m}$ \\
\hline s38584 & 34493 & 1464 & 23 & 8 & 567274 & 13614576 & $1.64 \%$ & 160 & 1234.35 & $81 \mathrm{~m}$ \\
\hline Average & - & - & - & 37 & 442862 & 7884415 & $9.12 \%$ & 704 & 478.49 & $64 \mathrm{~m}$ \\
\hline
\end{tabular}

TABLE IX

EXPERIMENTAL Results FOR TEST SETS From [11] TARgeting RANDOM-PATTERn-RESistant Faults WITH SCAN-ChaIn REORGANIZATION (ASSUMING 32 SCAN ChaINS FOR EACH CIRCUIT)

\begin{tabular}{c|c|c|c|c|c|c|c|c|c|c}
\hline \hline & $\begin{array}{c}\text { No. of } \\
\text { test } \\
\text { cubes }\end{array}$ & $\begin{array}{c}\text { No. of } \\
\text { scan } \\
\text { cells }\end{array}$ & $\begin{array}{c}\text { Length } \\
\text { of scan } \\
\text { chain }\end{array}$ & $\begin{array}{c}\text { No. of } \\
\text { configurations }\end{array}$ & $\begin{array}{c}\text { No. of } \\
\text { BIST } \\
\text { patterns }\end{array}$ & $\begin{array}{c}\text { Testing } \\
\text { time (clock } \\
\text { cycles) }\end{array}$ & $\begin{array}{c}\text { Hardware } \\
\text { overhead } \\
\text { (percentage) }\end{array}$ & $\begin{array}{c}\text { Storage } \\
\text { requirement } \\
\text { (bits) }\end{array}$ & $\begin{array}{c}\text { Encoding } \\
\text { efficiency }\end{array}$ & $\begin{array}{c}\text { CPU } \\
\text { time }\end{array}$ \\
\hline s5378 & 39 & 214 & 7 & 5 & 3269 & 26152 & $4.80 \%$ & 60 & 10.27 & $<1 \mathrm{~m}$ \\
\hline s9234 & 698 & 247 & 8 & 34 & 34341 & 309069 & $15.31 \%$ & 544 & 32.53 & $2 \mathrm{~m}$ \\
\hline s13207 & 556 & 700 & 22 & 5 & 54776 & 1259848 & $1.53 \%$ & 80 & 106.71 & $3 \mathrm{~m}$ \\
\hline s15850 & 654 & 611 & 20 & 22 & 26968 & 566328 & $5.38 \%$ & 330 & 45.15 & $1 \mathrm{~m}$ \\
\hline s38417 & 2219 & 1664 & 52 & 120 & 103653 & 5493609 & $11.70 \%$ & 2040 & 28.66 & $18 \mathrm{~m}$ \\
\hline s38584 & 441 & 1464 & 46 & 10 & 21282 & 1000254 & $1.10 \%$ & 150 & 48.74 & $2 \mathrm{~m}$ \\
\hline Average & - & - & - & 33 & 40714 & 1442543 & $6.64 \%$ & 534 & 45.34 & $5 \mathrm{~m}$ \\
\hline
\end{tabular}

$\mathrm{s}$ for the remaining scan chains. Similarly for $\mathrm{s} 38584$, when a 64-bit LFSR is used to drive 64 scan chains, only 59 multiplexers are needed (the remaining five scan chains are directly connected to the LFSR taps) and the number of tristate gates is only 276.

Table XIII compares the storage requirements of the proposed approach with hybrid BIST based on weighted pseudorandom patterns [16], test vector encoding using partial LFSR reseeding [18], the BIST scheme based on reseeding of folding counter [11], and two-dimensional test-data compression [22]. The results for the proposed approach are taken from Table IX.
The results presented for these methods in the literature rely on 10000 initial pseudorandom patterns to eliminate the easy to detect faults, except for [16], which uses 32000 pseudorandom patterns. The results show that in all but one case, the proposed approach requires less storage than other methods listed in the table. (The hybrid BIST method [16] requires less storage for s9234.) Despite requiring more storage, methods such as [16] and [18] generally require less hardware overhead than the proposed technique. Thus, the choice of an appropriate BIST method for particular CUT must be made by considering a combination of these factors. 
TABLE $X$

EXPERIMENTAL RESUlts FOR TEST SETS From [11] TARgEting RANDOM-PatTERN-RESistant Faults With SCAN-Chain REORGANIZATION (ASSUMING 64 SCAN CHAINS FOR EACH CiRCUIT)

\begin{tabular}{c|c|c|c|c|c|c|c|c|c|c}
\hline \hline & $\begin{array}{c}\text { No. of } \\
\text { test } \\
\text { cubes }\end{array}$ & $\begin{array}{c}\text { No. of } \\
\text { scan } \\
\text { cells }\end{array}$ & $\begin{array}{c}\text { Length } \\
\text { of scan } \\
\text { chain }\end{array}$ & $\begin{array}{c}\text { No. of } \\
\text { configurations }\end{array}$ & $\begin{array}{c}\text { Bo. of } \\
\text { BIST } \\
\text { patterns }\end{array}$ & $\begin{array}{c}\text { Testing } \\
\text { time (clock } \\
\text { cycles) }\end{array}$ & $\begin{array}{c}\text { Hardware } \\
\text { overhead } \\
\text { (percentage) }\end{array}$ & $\begin{array}{c}\text { Storage } \\
\text { requirement } \\
\text { (bits) }\end{array}$ & $\begin{array}{c}\text { Encoding } \\
\text { efficiency }\end{array}$ & $\begin{array}{c}\text { CPU } \\
\text { time }\end{array}$ \\
\hline s13207 & 556 & 700 & 11 & 4 & 21001 & 252012 & $2.23 \%$ & 60 & 142.28 & $1 \mathrm{~m}$ \\
\hline s15850 & 654 & 611 & 10 & 19 & 21173 & 232903 & $8.68 \%$ & 285 & 52.27 & $2 \mathrm{~m}$ \\
\hline s38417 & 2219 & 1664 & 26 & 53 & 115209 & 3110643 & $10.06 \%$ & 901 & 64.90 & $17 \mathrm{~m}$ \\
\hline s38584 & 441 & 1464 & 23 & 8 & 10236 & 245664 & $1.64 \%$ & 112 & 65.28 & $1 \mathrm{~m}$ \\
\hline 4verage & - & - & - & 21 & 41905 & 960306 & $5.65 \%$ & 340 & 81.18 & $5 \mathrm{~m}$ \\
\hline
\end{tabular}

TABLE XI

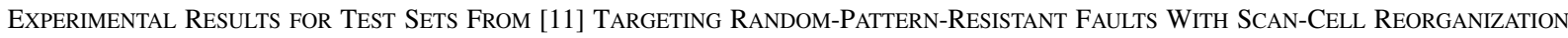
AND A FiXed Number of PATterns PER CONFiguration (ASSUMing 32 SCAN CHAins For EACH CirCUit)

\begin{tabular}{c|c|c|c|c|c|c|c|c|c}
\hline \hline & $\begin{array}{c}\text { No. of } \\
\text { test } \\
\text { cubes }\end{array}$ & $\begin{array}{c}\text { No. of } \\
\text { scan } \\
\text { cells }\end{array}$ & $\begin{array}{c}\text { Length } \\
\text { of scan } \\
\text { chain }\end{array}$ & $\begin{array}{c}\text { No. of } \\
\text { configurations }\end{array}$ & $\begin{array}{c}\text { No. of } \\
\text { BIST } \\
\text { patterns }\end{array}$ & $\begin{array}{c}\text { Testing } \\
\text { time (clock } \\
\text { cycles) }\end{array}$ & $\begin{array}{c}\text { Hardware } \\
\text { overhead } \\
\text { (percentage) }\end{array}$ & $\begin{array}{c}\text { Storage } \\
\text { requirement } \\
\text { (bits) }\end{array}$ & $\begin{array}{c}\text { CPU } \\
\text { time }\end{array}$ \\
\hline s5378 & 39 & 214 & 7 & 5 & 4003 & 32024 & $4.81 \%$ & 0 & $<1 \mathrm{~m}$ \\
\hline s9234 & 698 & 247 & 8 & 37 & 36001 & 324009 & $16.49 \%$ & 0 & $2 \mathrm{~m}$ \\
\hline s13207 & 556 & 700 & 22 & 8 & 8000 & 184000 & $2.43 \%$ & 0 & $<1 \mathrm{~m}$ \\
\hline s15850 & 654 & 611 & 20 & 24 & 23002 & 483042 & $5.35 \%$ & 0 & $2 \mathrm{~m}$ \\
\hline s38417 & 2219 & 1664 & 52 & 129 & 128001 & 6784053 & $12.59 \%$ & 0 & $21 \mathrm{~m}$ \\
\hline s38584 & 441 & 1464 & 46 & 12 & 11001 & 517047 & $1.29 \%$ & 0 & $1 \mathrm{~m}$ \\
\hline 4verage & - & - & - & 36 & 35001 & 1387363 & $7.16 \%$ & 0 & $5 \mathrm{~m}$ \\
\hline
\end{tabular}

In Table XIV, we compare the proposed method with scan-based three-weight weighted random BIST [33]. Since no storage of seeds or control bits is required in [33], we use the results from Table XI for comparison. The third column of Table XIV lists the number of pseudorandom patterns required to achieve $100 \%$ coverage of detectable single stuck-at faults, as reported in [1] and [33]. The total number of patterns listed for our approach is obtained by adding 10000 to the number of patterns listed in Table XI. The testing times listed in the table are obtained by assuming a $20 \mathrm{MHz}$ scan-clock frequency. The testing time for the proposed approach is less, even though [33] requires a smaller number of patterns for some circuits. This is because we use a multiple scan-chain architecture, whereas [33] is based on a single scan-chain architecture. In order to compare the hardware overhead of the proposed method with [33], we calculate the gate equivalent (GE) value for the hardware overhead using the same method as in [33]: $0.5 n$ for an $n$-input NAND or NOR gate, and 0.5 for an inverter. We also use 0.5 as the GE value for a transmission gate, and a GE value of 4 for a flip-flop. The use of a single scan-chain architecture ensures that the hardware overhead in [33] is lower; however, in order to scale three-weight weighted random BIST to multiple scan chains, separate decoding logic is needed for each scan chain, which contributes to increased hardware overhead. The parallel scheme in [33] requires even less hardware, but it relies on explicit control of the set and reset signals of the flip-flops after scan-cell reordering. Slightly lower GE counts are reported in [20] for the BIST hardware; however, the approach in [20] only addresses single-scan chains. Comparable, and sometimes even lower, hardware overhead is reported for seed encoding in [2]; however, the overhead figures in [2] do not include the size of the LFSR, which is determined by the number of specified bits in a test vector, and can be as high as 500 bits in many cases. While our proposed approach is based on the embedding of precomputed test sets without fault simulation, three-valued fault simulation is interleaved with the synthesis of the BIST architecture to obtain low hardware overhead in both [34] and [35]. Thus, a direct comparison between the proposed approach and [34] and [35] is difficult. Finally, the overlap between the experimental results reported in [31] and in this paper is limited to only one common benchmark circuit; hence, it is not meaningful to compare our results with [31].

We also implemented a phase shifter using the synthesis procedure presented in [25] and compared the hardware overhead of the phase shifter to that of the proposed BIST architecture as shown in Table XV. The hardware overhead for the phase shifter is obtained in the same way as we obtain the hardware overhead for the proposed architecture. The hardware overheads for the RIN are the minimum, average, and maximum values from Tables XI and XII with the same number of scan chains. The results 
TABLE XII

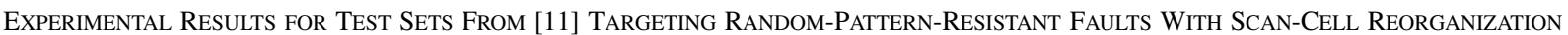
AND A FiXED NuMBER OF PATTERNS PER CONFIGURATION (ASSUMING 64 SCAN CHAINS FOR EACH CIRCUIT)

\begin{tabular}{|c|c|c|c|c|c|c|c|c|c|c|}
\hline \multirow[b]{2}{*}{ Circuit } & \multirow{2}{*}{$\begin{array}{c}\text { No. of } \\
\text { test } \\
\text { cubes }\end{array}$} & \multirow{2}{*}{$\begin{array}{l}\text { No. of } \\
\text { scan } \\
\text { cells }\end{array}$} & \multirow{2}{*}{$\begin{array}{l}\text { Length } \\
\text { of scan } \\
\text { chain }\end{array}$} & \multicolumn{2}{|c|}{$\begin{array}{c}\text { No. of } \\
\text { configurations }\end{array}$} & \multirow{2}{*}{$\begin{array}{l}\text { No. of } \\
\text { BIST } \\
\text { patterns }\end{array}$} & \multirow{2}{*}{$\begin{array}{c}\text { Testing } \\
\text { time } \\
\text { (clock } \\
\text { cycles) }\end{array}$} & \multirow{2}{*}{$\begin{array}{c}\text { Hardware } \\
\text { overhead } \\
\text { (percentage) }\end{array}$} & \multirow{2}{*}{$\begin{array}{c}\text { Storage } \\
\text { requirement } \\
\text { (bits) }\end{array}$} & \multirow[b]{2}{*}{$\begin{array}{l}\mathrm{CPU} \\
\text { time }\end{array}$} \\
\hline & & & & $\begin{array}{l}\text { Actual } \\
\text { results }\end{array}$ & $\begin{array}{c}\text { Analysis } \\
\text { results }\end{array}$ & & & & & \\
\hline s13207 & 556 & 700 & 11 & 7 & 8.7 & 6001 & 72012 & $3.74 \%$ & 0 & $1 \mathrm{~m}$ \\
\hline $\mathrm{s} 15850$ & 654 & 611 & 10 & 18 & 16.0 & 17649 & 194139 & $8.24 \%$ & 0 & $2 \mathrm{~m}$ \\
\hline s38417 & 2219 & 1664 & 26 & 61 & 60.0 & 60098 & 1622646 & $11.58 \%$ & 0 & $19 m$ \\
\hline s38584 & 441 & 1464 & 23 & 7 & 7.5 & 6004 & 144096 & $1.41 \%$ & 0 & $1 \mathrm{~m}$ \\
\hline Average & - & - & - & 23 & 23.1 & 22438 & 508223 & $6.24 \%$ & 0 & $6 \mathrm{~m}$ \\
\hline
\end{tabular}

TABLE XIII

COMPARISON OF STORAGE (IN BITS) REQUIRED FOR VARIOUS BIST METHODS

\begin{tabular}{c|c|c|c|c|c}
\hline \hline Circuit & $\begin{array}{c}\text { Hybrid } \\
\text { BIST [16] }\end{array}$ & $\begin{array}{c}\text { Partial } \\
\text { Reseeding [18] }\end{array}$ & $\begin{array}{c}\text { Reseeding of } \\
\text { folding counter [11] }\end{array}$ & $\begin{array}{c}\text { Two-dimensional } \\
\text { compression [22] }\end{array}$ & $\begin{array}{c}\text { Proposed } \\
\text { approach }\end{array}$ \\
\hline $\mathrm{s} 5378$ & N/A & 502 & 132 & 196 & 60 \\
\hline $\mathrm{s} 9234$ & 371 & 5013 & 2310 & 3800 & 544 \\
\hline $\mathrm{s} 13207$ & 110 & 3008 & 247 & 1044 & 80 \\
\hline $\mathrm{s} 15850$ & 535 & 5204 & 2403 & 3360 & 330 \\
\hline $\mathrm{s} 38417$ & 2663 & 24513 & 6802 & 11214 & 2040 \\
\hline $\mathrm{s} 38584$ & 615 & 2942 & 660 & 2891 & 150 \\
\hline
\end{tabular}

in the table show that the average hardware overhead of the proposed RIN architecture is sometimes slightly larger than that of the phase shifter. An advantage of the phase shifter is that it is CUT-independent; however, the test patterns generated by the LFSR and the phase shifter do not guarantee complete test set embedding and fault coverage. The proposed RIN architecture can embed all the deterministic test patterns and provide the same coverage as the deterministic test set. This is highlighted in Table XVI, which shows the number of patterns embedded and fault efficiency obtained using RIN and a phase shifter with shift distance 1024 , respectively. The test patterns are taken from [11], and they target hard faults that remain undetected after 10000 pseudorandom patterns are applied. For the RIN, we fix the number of patterns per configuration to 1000 as in Table XI.

In all of the above experiments, we use the proposed synthesis procedure with a random seed for the LFSR. In order to investigate the influence of the initial seed on the results, we carried out the experiments with 20 randomly selected initial seeds for the test set from [11], targeting all faults with scan-cell reorganization and scan chains. The statistics on the number of configurations are listed in Table XVII(A). We also carried out the same experiments for the test set from [11], targeting random-pattern-resistant faults and listed results in Table XVII(B). The results show that the number of configurations depends on the initial seed. However, the dependency is not very significant due in part to the reconfigurability of the interconnection network. A detailed study of the seed selection problem is left for future work.
In order to evaluate the effectiveness of the proposed approach for large circuits, we applied the method to test sets for two production circuits from IBM, namely CKT1 and CKT2. CKT1 is a logic core consisting of 51082 gates and its test set provides $99.80 \%$ fault coverage. CKT2 is a logic core consisting of 94340 gates and its test set provides $99.76 \%$ fault coverage. The number of scan chains is fixed to 64 and 128 for each of these two circuits. We modified the simulation procedure such that the configuration of the interconnection network can be changed during the shifting in of a test cube, and we set the parameter MaxSkipPatterns to 0. Accordingly, in the proposed BIST architecture shown in Fig. 2(a), the stored control bits are the number of bits per configuration instead of the number of patterns per configuration, and the pattern counter is replaced by a bit counter that counts the number of bits that have been shifted into the scan chains. Table XVIII lists the results for these two industrial circuits. Since we do not have the gate-level netlists for these two circuits, we compute the hardware overhead for the proposed BIST architecture for these two circuits in GEs, and the percentage hardware overhead is obtained from the ratio of the amount of BIST hardware in GEs to the GE count of the CUT. The hardware overhead is less than $10 \%$, and very high encoding efficiency (up to 77.71) is achieved for both circuits. As mentioned above, we allow the configuration of the interconnection network to be changed during the shifting in of a test cube. Table XIX, Figs. 10 and 11 present the statistics on the number of reconfigurations per test cube. The number of intrapattern configurations is small for both circuits. 
TABLE XIV

COMPARISON WITH THREE-WEIGHT WEIGHTED RANDOM BIST

\begin{tabular}{|c|c|c|c|c|c|c|c|c|c|c|c|}
\hline \multirow[b]{2}{*}{ Circuit } & \multirow[b]{2}{*}{$\begin{array}{l}\text { No. of } \\
\text { scan } \\
\text { cells }\end{array}$} & \multirow[b]{2}{*}{$\begin{array}{l}\text { Required } \\
\text { random } \\
\text { patterns }\end{array}$} & \multicolumn{6}{|c|}{ 3-weight weighted random BIST [33] } & \multicolumn{3}{|c|}{ Proposed approach } \\
\hline & & & $\begin{array}{l}\text { No. of } \\
\text { random } \\
\text { patterns }\end{array}$ & $\begin{array}{c}\text { No. of } \\
\text { weighted } \\
\text { patterns }\end{array}$ & $\begin{array}{c}\text { Total } \\
\text { no. of } \\
\text { patterns }\end{array}$ & $\begin{array}{l}\text { Testing } \\
\text { time } \\
\text { (ms) }\end{array}$ & $\begin{array}{c}\text { Hardware } \\
\text { overhead in } \\
\text { GEs (parallel) }\end{array}$ & $\begin{array}{l}\text { Hardware } \\
\text { overhead in } \\
\text { GEs (serial) }\end{array}$ & $\begin{array}{c}\text { Total } \\
\text { no. of } \\
\text { patterns }\end{array}$ & $\begin{array}{c}\text { Testing } \\
\text { time } \\
\text { (ms) }\end{array}$ & $\begin{array}{c}\text { Hardware } \\
\text { overhead } \\
\text { (GEs) }\end{array}$ \\
\hline s5378 & 214 & $>10 \mathrm{M}$ & 4000 & 5120 & 9120 & 98.04 & 16 & 86.5 & 14003 & 5.60 & 103.5 \\
\hline s9234 & 247 & $11 \mathrm{M}$ & 32000 & 11264 & 43264 & 536.47 & 91 & 146.5 & 46001 & 20.70 & 748.5 \\
\hline s13207 & 700 & $264 K$ & 64000 & 6144 & 70144 & 2458.55 & 16.5 & 120.0 & 18000 & 20.70 & 157.5 \\
\hline s15850 & 611 & $>100 \mathrm{M}$ & 64000 & 21504 & 85504 & 2616.42 & 82 & 264.5 & 33002 & 34.65 & 478.5 \\
\hline s38417 & 1664 & $>100 \mathrm{M}$ & 32000 & 53248 & 85248 & 7096.90 & 169.5 & 626.6 & 138001 & 365.70 & 2680.5 \\
\hline s38584 & 1464 & $>100 \mathrm{M}$ & 2000 & 16384 & 18384 & 1346.63 & 30 & 197.0 & 21001 & 49.35 & 240 \\
\hline
\end{tabular}

TABLE XV

Comparison of the Hardware Overhead of the Proposed Method With That of a Phase SHIFTER

\begin{tabular}{|c|c|c|c|c|c|c|c|}
\hline \multirow{2}{*}{$\begin{array}{c}\text { LFSR } \\
\text { length (bits) }\end{array}$} & \multirow{2}{*}{$\begin{array}{c}\text { No. of } \\
\text { scan chains }\end{array}$} & \multirow{2}{*}{$\begin{array}{l}\text { Minimum shifts between } \\
\text { scan chains (two values } \\
\text { of shift distance) }\end{array}$} & \multirow{2}{*}{$\begin{array}{l}\text { Maximum XOR } \\
\text { inputs for } \\
\text { any scan chain }\end{array}$} & \multirow{2}{*}{$\begin{array}{l}\text { Hardware overhead } \\
\text { of the phase shifter }\end{array}$} & \multicolumn{3}{|c|}{$\begin{array}{c}\text { Hardware overhead } \\
\text { of the RIN }\end{array}$} \\
\hline & & & & & $\operatorname{Max}$ & Min & Avg \\
\hline 64 & 32 & $1024(16)$ & $18(9)$ & $1273.9(443.1)$ & 2680.5 & 103.5 & 734.8 \\
\hline 64 & 64 & $1024(16)$ & $19(12)$ & $2482.8(1199.7)$ & 2192.9 & 251.5 & 837.0 \\
\hline 32 & 32 & $1024(16)$ & $7(7)$ & $476.0(462.5)$ & 2680.5 & 103.5 & 734.8 \\
\hline 32 & 64 & $1024(16)$ & $7(7)$ & $857.8(845.2)$ & 2192.9 & 251.5 & 837.0 \\
\hline
\end{tabular}

TABLE XVI

COMPARISON OF TEST-SET EMBEDDING BETWEEN RIN AND A PHASE SHIFTER

\begin{tabular}{|c|c|c|c|c|c|c|c|}
\hline \multirow[b]{2}{*}{ Circuit } & \multirow[b]{2}{*}{$\begin{array}{l}\text { No. of } \\
\text { deterministic } \\
\text { test patterns }\end{array}$} & \multicolumn{3}{|c|}{ Results for RIN } & \multicolumn{3}{|c|}{ Results for phase shifter } \\
\hline & & $\begin{array}{l}\text { No. of patterns } \\
\text { required for } \\
\text { embedding }\end{array}$ & $\begin{array}{c}\text { No. of } \\
\text { deterministic } \\
\text { patterns embedded }\end{array}$ & $\begin{array}{c}\text { Fault } \\
\text { efficiency } \\
\text { (percentage) }\end{array}$ & $\begin{array}{l}\text { No. of patterns } \\
\text { considered for } \\
\text { embedding }\end{array}$ & $\begin{array}{c}\text { No. of } \\
\text { deterministic } \\
\text { patterns embedded }\end{array}$ & $\begin{array}{c}\text { Fault } \\
\text { efficiency } \\
\text { (percentage) }\end{array}$ \\
\hline s5378 & 39 & 4003 & 39 & $100 \%$ & 14003 & 8 & $98.9 \%$ \\
\hline s9234 & 698 & 36001 & 698 & $100 \%$ & 46001 & 117 & $94.0 \%$ \\
\hline s13207 & 556 & 8000 & 556 & $100 \%$ & 18000 & 191 & $96.5 \%$ \\
\hline s 15850 & 654 & 23002 & 654 & $100 \%$ & 33002 & 51 & $95.9 \%$ \\
\hline s38417 & 2219 & 128001 & 2219 & $100 \%$ & 138001 & 140 & $97.9 \%$ \\
\hline s38584 & 441 & 11001 & 441 & $100 \%$ & 21001 & 207 & $99.2 \%$ \\
\hline
\end{tabular}

\section{CONCLUSION}

We have presented a new approach for deterministic BIST based on the use of an RIN. The RIN is placed between the outputs of pseudorandom pattern generator, e.g., an LFSR, and the scan inputs of the CUT. It consists only of multiplexer switches and is designed using a synthesis procedure that takes as inputs the pseudorandom sequence from the LFSR and the deterministic test cubes for the CUT. The connections between the LFSR and the scan chains can be changed dynamically (reconfigured) during a test session. In this way, the RIN is used to match the LFSR outputs to the set of test cubes $T_{D}$. The control data bits used for reconfiguration guarantee that $T_{D}$ is embedded in the test patterns applied to the CUT. We have shown through several sets of experiments that the proposed approach requires very little hardware overhead and only a modest amount of CPU time. We have also shown that the fewer control bits are required compared to the storage required for reseeding methods or for hybrid BIST. Finally, as a nonintrusive BIST solution, the proposed approach does not require any circuit redesign and it has minimal impact on circuit performance.

We are currently extending this work to ensure that undesirable input patterns that cause problems such as bus contention are forwarded to the scan chains by the RIN. It appears that this problem, which is typical of most logic BIST techniques, can be handled by suitably modifying the RIN synthesis procedure. 
TABLE XVII

Statistics on the Number of Configurations With Random SEEDS FOr Test Sets From [11] TARgeting (A) All Faults and (B) RANDOM-PATTERN-RESISTANT FAULTS, With SCAN-CHAIN REORGANIZATION (ASSUMING 32 SCAN CHAINS FOR EACH CiRCUIT)

\begin{tabular}{c|c|c|c|c}
\hline \hline Circuit & Minimum & Maximum & Mean & $\begin{array}{c}\text { Standard } \\
\text { deviation }\end{array}$ \\
\hline s5378 & 6 & 9 & 7.2 & 0.83 \\
\hline s9234 & 29 & 33 & 30.5 & 1.10 \\
\hline s13207 & 10 & 14 & 11.85 & 1.18 \\
\hline s15850 & 16 & 20 & 17.5 & 1.24 \\
\hline s38417 & 180 & 192 & 185.9 & 3.23 \\
\hline s38584 & 9 & 12 & 9.8 & 0.89 \\
\hline
\end{tabular}

(A)

\begin{tabular}{c|c|c|c|c}
\hline \hline Circuit & Minimum & Maximum & Mean & $\begin{array}{c}\text { Standard } \\
\text { deviation }\end{array}$ \\
\hline $\mathrm{s} 5378$ & 3 & 5 & 3.55 & 0.60 \\
\hline $\mathrm{s} 9234$ & 32 & 36 & 33.7 & 1.38 \\
\hline $\mathrm{s} 13207$ & 5 & 8 & 5.95 & 0.89 \\
\hline $\mathrm{s} 15850$ & 19 & 25 & 21.8 & 1.51 \\
\hline $\mathrm{s} 38417$ & 118 & 129 & 121.45 & 3.07 \\
\hline $\mathrm{s} 38584$ & 9 & 12 & 10.8 & 0.83 \\
\hline
\end{tabular}

(B)

TABLE XVIII

RESUlTS FOR TEST CUBES FOR CIRCUITS FROM IBM

\begin{tabular}{|c|c|c|c|c|c|c|c|c|c|c|}
\hline Circuit & $\begin{array}{c}\text { No. of } \\
\text { test } \\
\text { cubes }\end{array}$ & $\begin{array}{l}\text { No. of } \\
\text { scan } \\
\text { cells }\end{array}$ & $\begin{array}{l}\text { No. of } \\
\text { scan } \\
\text { chains }\end{array}$ & $\begin{array}{c}\text { Length } \\
\text { of scan } \\
\text { chain (bits) }\end{array}$ & $\begin{array}{c}\text { No. of } \\
\text { configurations }\end{array}$ & $\begin{array}{c}\text { Testing } \\
\text { time (clock } \\
\text { cycles) }\end{array}$ & $\begin{array}{c}\text { Hardware overhead } \\
\text { in GEs, and as a } \\
\text { percentage }\end{array}$ & $\begin{array}{c}\text { Storage } \\
\text { requirement } \\
\text { (bits) }\end{array}$ & $\begin{array}{l}\text { Encoding } \\
\text { efficiency }\end{array}$ & $\begin{array}{l}\mathrm{CPU} \\
\text { time }\end{array}$ \\
\hline \multirow{2}{*}{ CKT1 } & \multirow{2}{*}{17176} & \multirow{2}{*}{12256} & 64 & 192 & 1792 & 1351104 & $68145.5(8.52 \%)$ & 21504 & 46.79 & $1 \mathrm{~h} 37 \mathrm{~m}$ \\
\hline & & & 128 & 96 & 1079 & 566496 & $75579.5(9.45 \%)$ & 12948 & 77.71 & $1 \mathrm{~h} 26 \mathrm{~m}$ \\
\hline \multirow{2}{*}{ CKT2 } & \multirow{2}{*}{43079} & \multirow{2}{*}{22216} & 64 & 348 & 3221 & 4051764 & $124062.5(7.26 \%)$ & 38652 & 26.03 & $6 \mathrm{~h} 35 \mathrm{~m}$ \\
\hline & & & 128 & 174 & 1828 & 2338005 & $128009.5(7.49 \%)$ & 21936 & 45.87 & $6 \mathrm{~h} 06 \mathrm{~m}$ \\
\hline
\end{tabular}

TABLE XIX

NUMBER OF ReCONFIGURATIONS PER PATTERN FOR TEST SETS From IBM

\begin{tabular}{l|c|c|c|c|c|c}
\hline \hline \multirow{2}{*}{ Circuit } & \multirow{2}{*}{$\begin{array}{c}\text { No. of } \\
\text { scan chains }\end{array}$} & \multirow{2}{*}{$\begin{array}{c}\text { Length of a test cube } \\
\text { per scan chain (bits) }\end{array}$} & \multicolumn{4}{|c}{ No. of reconfigurations per pattern } \\
\cline { 4 - 7 } & & Minimum & Maximum & Mean & Standard deviation \\
\hline \multirow{2}{*}{ CKT1 } & 64 & 192 & 0 & 3 & 0.11 & 0.0210 \\
\cline { 2 - 7 } & 128 & 96 & 0 & 3 & 0.07 & 0.0354 \\
\hline \multirow{2}{*}{ CKT2 } & 64 & 348 & 0 & 3 & 0.11 & 0.0204 \\
\cline { 2 - 7 } & 128 & 174 & 0 & 15 & 0.06 & 0.3018 \\
\hline
\end{tabular}

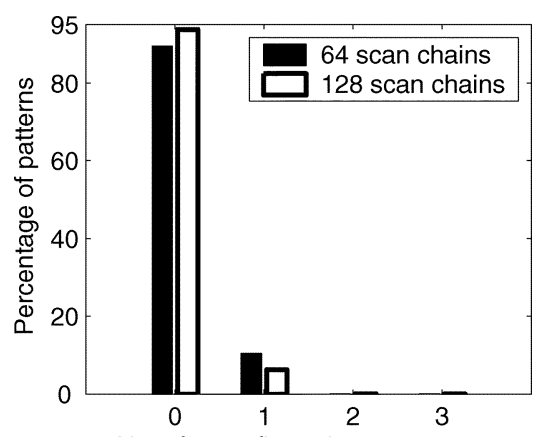

No. of reconfigurations per pattern

Fig. 10. Number of patterns versus the number of reconfigurations needed for CKT1.

\section{ACKNOWLEDGMENT}

The authors thank Prof. S. Hellebrand of the University of Innsbruck, Innsbruck, Austria, for providing the test cubes used in [11]. They also thank S. Swaminathan of the IBM Corporation for providing the test cubes for the production circuits from IBM, and the anonymous reviewers for many constructive comments. 


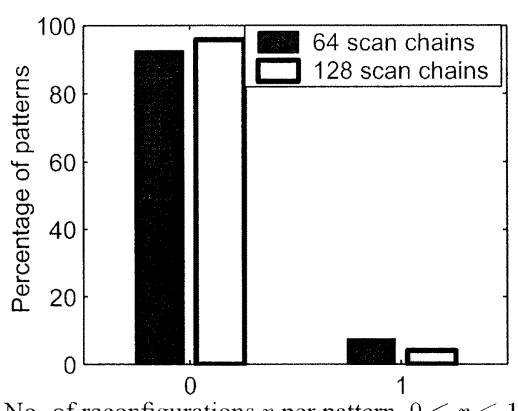

No. of reconfigurations $r$ per pattern, $0 \leq r \leq 1$ (a)

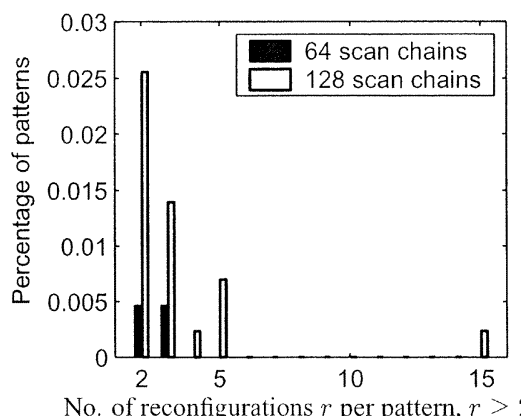

(b)

Fig. 11. Number of patterns versus the number of reconfigurations needed for CKT2.

\section{REFERENCES}

[1] M. F. AlShaibi and C. R. Kime, "MFBIST: A BIST method for random pattern resistant circuits," in Proc. Int. Test Conf., 1996, pp. 176-185.

[2] A. A. Al-Yamani and E. J. McCluskey, "Seed encoding with LFSRs and cellular automata," in Proc. ACM/IEEE Design Automation Conf., 2003, pp. 560-565.

[3] C. Barnhart, V. Brunkhorst, F. Distler, O. Farnsworth, B. Keller, and B. Koenemann, "OPMISR: The foundation for compressed ATPG vectors," in Proc. Int. Test Conf., 2001, pp. 748-757.

[4] I. Bayraktaroglu and A. Orailoglu, "Test volume and application time reduction through scan-chain concealment," in Proc. ACM/IEEE Design Automation Conf., 2001, pp. 151-155.

[5] A. Chandra and K. Chakrabarty, "Test data compression and test resource partitioning for system-on-a-chip using frequency-directed runlength (FDR) codes," IEEE Trans. Comput., vol. 52, pp. 1076-1088, Aug. 2003.

[6] - "System-on-a-chip test data compression and decompression architectures based on Golomb codes," IEEE Trans. Computer-Aided Design, vol. 20, pp. 355-368, Mar. 2001

[7] K.-T. Cheng and C.-J. Lin, "Timing driven test point insertion for fullscan and partial-scan BIST," in Proc. Int. Test Conf., 1995, pp. 506-514.

[8] A. El-Maleh, S. al Zahir, and E. Khan, "A geometric-primitives-based compression scheme for testing systems-on-chip," in Proc. VLSI Test Symp., 2001, pp. 54-59.

[9] P. T. Gonciari, B. Al-Hashimi, and N. Nicolici, "Improving compression ratio, area overhead, and test application time for system-on-a-chip test data compression/decompression," in Proc. Design, Automation Test Eur. Conf., 2002, pp. 604-611.

[10] I. Hamzaoglu and J. H. Patel, "Test set compaction algorithms for combinational circuits," in Proc. Int. Conf. Computer-Aided Design, 1998, pp. $283-289$.

[11] S. Hellebrand, H.-G. Liang, and H.-J. Wunderlich, "A mixed-mode BIST scheme based on reseeding of folding counters," in Proc. Int. Test Conf., 2000, pp. 778-784.

[12] G. Hetherington, T. Fryars, N. Tamarapalli, M. Kassab, A. Hassan, and J. Rajski, "Logic BIST for large industrial designs: Real issues and case studies," in Proc. Int. Test Conf., 1999, pp. 358-367.

[13] V. Iyengar, K. Chakrabarty, and B. T. Murray, "Deterministic built-in pattern generation for sequential circuits," J. Electron. Testing: Theory Applicat., vol. 15, pp. 97-115, 1999.

[14] A. Jas and N. A. Touba, "Test vector decompression via cyclical scan chains and its application to testing core-based design," in Proc. Int. Test Conf., 1998, pp. 458-464.

[15] A. Jas, J. Ghosh-Dastidar, and N. A. Touba, "Scan vector compression/decompression using statistical coding," in Proc. VLSI Test Symp., 1999, pp. 114-120.

[16] A. Jas, C. V. Krishna, and N. A. Touba, "Hybrid BIST based on weighted pseudo-random testing: A new test resource partitioning scheme," in Proc. VLSI Test Symp., 2001, pp. 2-8.

[17] B. Koenemann, C. Barnhart, B. Keller, T. Snethen, O. Farnsworth, and D. Wheater, "A SmartBIST variant with guaranteed encoding," in Proc. Asian Test Symp., 2001, pp. 325-330.

[18] C. V. Krishna, A. Jas, and N. A. Touba, "Test vector encoding using partial LFSR reseeding," in Proc. Int. Test Conf., 2001, pp. 885-893.

[19] C. V. Krishna and N. A. Touba, "Reducing test data volume using LFSR reseeding with seed compression," in Proc. Int. Test Conf., 2002, pp. $321-330$.
[20] W. Li, C. Yu, S. M. Reddy, and I. Pomeranz, "A scan BIST generation method using a Markov source and partial bit-fixing," in Proc. ACM/IEEE Design Automation Conf., 2003, pp. 554-559.

[21] L. Li and K. Chakrabarty, "Test data compression using dictionaries with fixed-length indices," in Proc. VLSI Test Symp., 2003, pp. 219-224.

[22] H.-G. Liang, S. Hellebrand, and H.-J. Wunderlich, "Two-dimensional test data compression for scan-based deterministic BIST," in Proc. Int. Test Conf., 2001, pp. 894-902.

[23] M. Nakao, S. Kobayashi, K. Hatayama, K. Iijima, and S. Terada, "Low overhead test point insertion for scan-based BIST," in Proc. Int. Test Conf., 1999, pp. 348-357.

[24] J. Rajski, J. Tyszer, and N. Zacharia, "Test data decompression for multiple scan designs with boundary scan," IEEE Trans. Comput., vol. 47, pp. 1188-1200, Nov. 1998.

[25] J. Rajski and J. Tyszer, "Design of phase shifters for BIST applications," in Proc. VLSI Test Symp., 1998, pp. 218-224.

[26] J. Rajski, J. Tyszer, M. Kassab, N. Mukherjee, R. Thompson, H. Tsai, A. Hertwig, N. Tamarapalli, G. Mrugalski, G. Eide, and J. Qian, "Embedded deterministic test for low-cost manufacturing test," in Proc. Int. Test Conf., 2002, pp. 301-310.

[27] S. Reda and A. Orailoglu, "Reducing test application time through test data mutation encoding," in Proc. Design, Automation Test Eur. Conf., 2002, pp. 387-393.

[28] S. M. Reddy, K. Miyase, S. Kajihara, and I. Pomeranz, "On test data volume reduction for multiple scan chain design," in Proc. VLSI Test Symp., 2002, pp. 103-108.

[29] L. Schafer, R. Dorsch, and H.-J. Wunderlich, "RESPIN++ - deterministic embedded test," in Proc. Eur. Test Workshop, 2002, pp. 37-44.

[30] C. Schotten and H. Meyr, "Test point insertion for an area efficient BIST," in Proc. Int. Test Conf., 1995, pp. 515-523.

[31] N. A. Touba and E. J. McCluskey, "Altering a pseudo-random bit sequence for scan based BIST," in Proc. Int. Test Conf., 1996, pp. 167-175.

[32] E. H. Volkerink, A. Khoche, and S. Mitra, "Packet-based input test data compression techniques," in Proc. Int. Test Conf., 2002, pp. 154-163.

[33] S. Wang, "Low hardware overhead scan based 3-weight weighted random BIST," in Proc. Int. Test Conf., 2001, pp. 868-877.

[34] H.-J. Wunderlich and G. Kiefer, "Bit-flipping BIST," in Proc. Int. Conf. Computer-Aided Design, 1996, pp. 337-343.

[35] G. Kiefer and H.-J. Wunderlich, "Deterministic BIST with multiple scan chains," in Proc. Int. Test Conf., 1998, pp. 1057-1064.

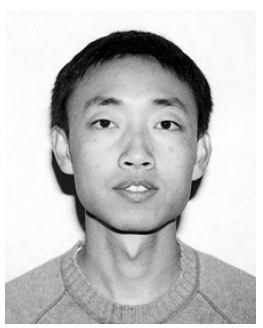

Lei Li received the B.S. and M.S. degrees in electrical engineering from Peking University, Beijing, China, in 1996 and 1999, respectively, and the M.S. degree in electrical and computer engineering in 2002 from Duke University, Durham, NC, where he is currently pursuing the Ph.D. degree in electrical and computer engineering.

He is a currently a Research Assistant at Duke University. His research interests are in the field of VLSI testing, with an emphasis on the techniques reducing test data volume and test application time. 


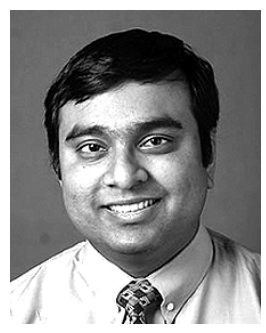

Krishnendu Chakrabarty (S'92-M'96-SM'00) received the B.Tech. degree from the Indian Institute of Technology, Kharagpur, India, in 1990, and the M.S.E. and Ph.D. degrees from the University of Michigan, Ann Arbor, in 1992 and 1995, respectively, all in computer science and engineering.

$\mathrm{He}$ is currently an Associate Professor of Electrical and Computer Engineering at Duke University, Durham, NC. From 2000 to 2002, he was also a Mercator Visiting Professor at the University of Potsdam, Potsdam, Germany. His current research projects include: design and testing of system-on-a-chip integrated circuits; embedded real-time systems; distributed sensor networks; modeling, simulation, and optimization of microelectrofluidic systems; microfluidics-based chip cooling. $\mathrm{He}$ is a coauthor of two books: Microelectrofluidic Systems: Modeling and Simulation (Boca Raton, FL: CRC Press, 2002) and Test Resource Partitioning for System-on-a-Chip (Norwell, MA: Kluwer, 2002), and an editor of SOC (System-on-a-Chip) Testing for Plug and Play Test Automation (Norwell, MA: Kluwer, 2002). He has published over 160 papers in journals and refereed conference proceedings, and holds a US patent in BIST.

Dr. Chakrabarty is a Member of ACM, ACM SIGDA, and Sigma Xi. He is a recipient of the National Science Foundation Early Faculty (CAREER) Award and the Office of Naval Research Young Investigator Award. He received a best paper award at the 2001 Design, Automation, and Test in Europe (DATE) Conference. He is also the recipient of the Humboldt Research Fellowship, awarded by the Alexander von Humboldt Foundation, Germany. He is an Associate Editor of IEEE TRANSACTIONS ON COMPUTER-AIDED DESIGN OF INTEGRATED CIRCUITS AND SYSTEMS, an Editor of the Journal of Electronic Testing: Theory and Applications (JETTA), and a member of the editorial board for Sensor Letters and the Journal of Embedded Computing. He has also served as an Associate Editor of the IEEE TRANSACTIONS ON CIRCUITS AND SYSTEMS-PART II: ANALOG AND Digital Signal Processing. He serves as Vice Chair of Technical Activities of the IEEE's Test Technology Technical Council and is a Member of the program committees of several IEEE/ACM conferences and workshops. 